\title{
Psicoestimulación cognitiva y programa de actividades en el geriátrico San José de la Montaña: validación empírica de la capacidad cognitiva y social de sus residentes
}

\author{
Alejandro Gómez Ordoki \\ <ago2804@gmail.com>
}

\author{
Ainhoa Losa Pe-Menchaca \\ Residencia San José de la Montaña
}

\begin{abstract}
Kontrol, zorroztasun eta eraginkortasunez kudeatzeko gure kezka horrek bultzatu gaitu sortzea aplikazio informatiko batzuek, eta horien bidez izatea fidagarri eta sistematizatutako datuak gure egoitzako pertsona adinduen arreta integralean partaide diren arlo horietan. Artikulu honetan, aurkezten da zehazki, horretarako erabiltzen dugun tresna psiko-estimulazio programetarako, eta horrek ahalbidetzen du konparazioa egitea laneko terapeutek egunero jasotzen duten informazioaren eta eskala teorikoen arteko informazioetan ageri den aldea. Eskala teoriko horiek sarri zail gertatzen dira burutzeko, izan ere, egoitzan bizi direnek ezegonkortasun kognitiboa izan baitute. Modu honetan, bilatzen dugu bermatzea emaitza psikometrikoak datu enpirikoak erabiliz, eta bien arteko korrelazioa hutsala edo zalantzakoa gertatuz gero, berriz planteatzea une egokia eta balorazio kognitiborako produktua. Aipaturiko azken tresna horren azkeneko xedea da erabiltzaileei eskaintzen zaien arretan hobekuntza jarraia gertatzea, pertsonaren zentralitatea, partaidetza soziala eta gauzatze indibiduala sustatuz.
\end{abstract}

\section{GAKO-HITZAK:}

Balioztatze psikometrikoa, baliozkotze enpirikoa, korrelazioa, efizientzia, kontrola, kalitatea, berrikuntza.
Nuestra inquietud por gestionar según criterios de control, rigor y eficacia nos ha impulsado a crear aplicaciones informáticas que nos permiten contar con datos fiables y sistematizados de las diferentes áreas que intervienen en la asistencia integral de las personas mayores de nuestra residencia. Este artículo presenta, en concreto, la herramienta que utilizamos para ello en los programas de psicoestimulación, y que nos permite contrastar la observación diaria de las terapeutas ocupacionales con las mediciones realizadas con escalas teóricas, en ocasiones costosas de administrar, debido a la inestabilidad cognitiva de muchos de nuestros residentes. De esta forma, buscamos avalar con datos empíricos los resultados psicométricos y, en caso de nula o dudosa correlación entre ambos, replantear el momento y el producto de la valoración cognitiva. El objetivo último de este instrumento es facilitar la mejora continua de la atención que se presta a los usuarios, impulsando la centralidad de la persona, la participación social y la realización individual.

\section{Palabras Clave:}

Valoración psicométrica, validación empírica, correlación, eficiencia, control, calidad, innovación. 


\section{Contextualización: el respeto a la individualidad de la persona como fundamento de la atención residencial a personas mayores}

Es innegable la evolución experimentada por el perfil tipo del colectivo de personas mayores atendidas en los geriátricos de la CAPV. Tanto es así que los procesos para responder a las exigencias de la realidad asistencial actual poco tienen que ver con la manera de entender la prestación del servicio hace tan sólo unos años. El aumento de la esperanza media de vida, unido a la cada vez mayor profesionalización de los servicios sociosanitarios, plantean nuevos escenarios de trabajo y, en consecuencia, la implantación de métodos innovadores en la atención integral a las personas mayores.

Tal y como se especifica en la misión, visión y valores de la residencia San José de la Montaña (SJM), para asegurar el disfrute de una vida de calidad por parte de la persona mayor se aplican los principios fundamentales definidos en la resolución 46/91 de la Asamblea General de las Naciones Unidas, de 16 de diciembre de 1991:

- Independencia: posibilidad de que la persona siga eligiendo por sí misma su forma de vivir, de pensar, de actuar y de relacionarse.

- Participación: estar integrado en la sociedad y participar activamente en la misma, compartiendo con las generaciones más jóvenes su visión y necesidades.

- Asistencia (atención y cuidados): cuidar de su salud en todos sus aspectos, para poder realizarse personalmente en el marco de una existencia digna.

- Realización de los propios deseos (realización personal): desarrollo de su personalidad y de su potencial, dándole la oportunidad de participar en actividades de diferente tipo donde pueda expresarse.

- Dignidad: respetar su individualidad y reconocer su valor.

La política integrada de gestión de nuestra residencia respeta el cumplimiento escrupuloso de estos principios. El proyecto que planteamos, sin embargo, trata de actuar de manera más profunda en dos de esos pilares: la participación y la realización personal. Proponemos abordar de manera sistemática la gestión de los recursos comunitarios y, en consecuencia, cómo nos debemos relacionar con nuestro entorno más próximo y, por extensión, con la ciudad y/o la zona geográfica que nos delimita. Además, para conjugar este anhelo con la oportunidad de que las personas que viven en nuestro centro puedan continuar teniendo un papel activo dentro y fuera de la vida del centro, nos planteamos un abanico diverso de actividades que, de manera transversal, nos puedan ayudar a perseguir una serie de objetivos específicos que culminan en un objetivo general: mantener y dar valor a la persona mayor como agente activo de la sociedad.

A ningún profesional del sector se le escapa que una vida plenamente independiente en un recurso institucionalizado es harto compleja de lograr. El inevitable corsé organizativo derivado de la planificación del servicio a prestar impide, en muchos casos, un planteamiento sencillamente domiciliario de los problemas a resolver. Conciliar calendarios de trabajo con régimen hostelero y éste, a su vez, con la libertad de decisión que debemos respetar en personas adultas es casi imposible, especialmente cuando la amalgama de perfiles psicogeriátricos parece no tener fin con la cada vez mayor esperanza de vida en personas mayores. A pesar de ello, la residencia San José de la Montaña defiende la atención centrada en la persona como paradigma de funcionamiento en la prestación de servicios residenciales integrales. En consecuencia, velará por definir herramientas y caminos que garanticen maximizar, en la medida de lo posible, el disfrute de una vida independiente $y$, a su vez, integrada comunitariamente en el centro. Entendemos que el/la residente, como un ciudadano más, tiene derecho a interpretar su vida con libertad cuando el uso de la misma no atente contra los derechos de los demás ni contra los valores que rigen nuestros principios como organización.

\section{Objetivos del proyecto}

Sin lugar a dudas, el principal objetivo del proyecto es posibilitar que las personas mayores usuarias de servicios residenciales integrales puedan ser protagonistas de sus vidas dentro del centro y, asimismo, puedan seguir participando proactivamente en la vida comunitaria, como un agente más de la sociedad. En este sentido, deberán canalizarse todas las inquietudes que se puedan suscitar entre quienes son el eje sobre el que gira la prestación de servicios residenciales y que, en la inmensa mayoría de los casos, presentan una evidente dispersión de necesidades, en la medida que el abanico de capacidades es muy variado. En la actualidad, los centros geriátricos se caracterizan por atender a personas con un altísimo grado de deterioro físico $\mathrm{y}$, principalmente, cognitivo. Esta realidad dificulta sobremanera la libre elección y participación en las actividades, pero no por ello se desprecian las sugerencias de aquellas personas con capacidad cognitiva para presentarlas. Así, el sistema planteado contempla la oferta de programas de participación e intercambio con diferentes entidades, restringida a aquellas personas con facultades para ello ${ }^{1}$.

En cualquier caso, y dado que el conjunto de datos requieren de un análisis que concluya en la puesta en práctica de diferentes acciones sobre las que realizar los oportunos seguimientos, no debemos descuidar

${ }^{1}$ El modelo se desarrolla para un geriátrico de 59 plazas homologadas y se basa en la explotación de los datos observados durante el último trienio (2012-2014). 
la parte de gestión implícita en el desarrollo del proyecto, cuyos objetivos se exponen seguidamente.

\section{1. Ámbito de la prestación de los servicios y la participación proactiva de nuestros residentes}

- Sensibilización: promover un mayor conocimiento y comprensión entre las generaciones más jóvenes y las de mayor edad, con el ánimo de eliminar o, al menos, relativizar los estereotipos habitualmente manejados. Para ello, valoraríamos la percepción a través de un cuestionario diseñado al efecto (test-retest), que sería administrado al comienzo y al final de la experiencia, con el objeto de observar la evolución experimentada.

- Potenciar el protagonismo del colectivo de personas mayores como agentes de la sociedad, a través de actividades que favorezcan su participación en la vida social y lúdica de la ciudad.

- Creación y fomento de una red estable de contactos con las entidades presentes en la comunidad, de manera que actividades ya consolidadas garanticen su presencia en nuestro centro y permitan investigar la posibilidad de contar con otras novedosas, que vayan ampliando nuestra cartera de actividades. El mapa de relaciones y comunicaciones de nuestro sistema de responsabilidad social corporativa facilitaría el mantenimiento de estos recursos.

- Búsqueda y/o definición de entornos en los que nuestros/as residentes no estén ni se sientan excluidos/as y, asimismo, de espacios en los que puedan desarrollar sus planes de vida, independientemente de la condiciones que presenten. En este sentido, nuestro centro ha invertido en la creación de diferentes ámbitos que simulen la vida del exterior en nuestro inmueble: salones de uso familiar con office incluido, patios abiertos con zona de deambulación y jardines con estanques y animales acuáticos, huerta cultivada entre el personal del centro y los/as residentes, programas de terapia con animales, zona de vending para potenciar la relación interfamiliar, espacios cerrados climatizados a modo de salones sociales, etc.

\section{2. Ámbito de la gestión}

Los objetivos generales son:

- Sistematizar el flujo de información en la que soportar la toma de decisiones, como centro garante de la vida activa de los residentes ${ }^{2}$. Mediante el análisis de los resultados de la atención personalizada de cada residente,

\footnotetext{
2 En algunas ocasiones, la utilización del género masculino debe ser interpretada como una licencia para simplificar el abanico de posibles dualidades. Por tanto, debe ser entendido en su sentido neutro.
}

debemos ser capaces de extraer conclusiones de colectividad.

- Involucrar al equipo de profesionales en la gestión con datos orientados a la mejora de la calidad de vida de los residentes.

- Disponer de información personalizada fiable para las familias y, a nivel estadístico, para el resto de agentes sociales y/o grupos de interés.

Los objetivos específicos son:

- Conseguir mejoras reales en las personas atendidas y evidenciarlas mediante indicadores de calidad de vida.

- Conseguir en el año 2014 la definición de objetivos cuantificables y medibles en el conjunto de actividades programadas y especiales del centro que redunden en la mejora de la calidad de vida de los residentes. Sistematización de la evaluación de las personas en las diferentes actividades ofertadas en el centro.

\section{Metodología de trabajo}

Más allá del cumplimiento de requisitos legales, la residencia San José de la Montaña pretende contar con una metodología de explotación de datos que tenga aplicación práctica en la atención personalizada y grupal de nuestros/as residentes; en otras palabras, buscamos diseñar herramientas de despliegue que nos permitan llegar a cada persona en cada uno de los ámbitos de actuación de nuestros servicios; y a la inversa, mediante los resultados de la atención personalizada de cada residente, llegar a identificar cuáles son sus necesidades reales y cómo deben ser medidas cualitativa y cuantitativamente. Esta iniciativa de mejora obedece a los requerimientos de información planteados por cada área de la organización: son las propias áreas las que han identificado las necesidades, los objetivos y, en consecuencia, las estrategias necesarias para cumplirlos. En el trayecto, debemos definir un circuito de información (emisor, receptor y canales) entre los diferentes agentes intervinientes que asegura la permanente revisión de los objetivos, sus planes y las correspondientes acciones correctoras o de mejora derivadas. La Figura 1 puede ayudarnos a interpretar la idea.

\section{1. Área psicológica}

Parte del trabajo del área de atención psicológica consiste en valorar semestralmente y de una manera estandarizada el estado cognitivo de las personas usuarias de nuestro centro. Una vez detectada la existencia de deterioro, se evalúa en qué grado y funciones se presenta, a través de una serie de pruebas neuropsicológicas extraídas de baterías estandarizadas que, combinadas entre sí, ofrecen información global de cada residente, de sus potencialidades y de aquellas funciones que presentan mayor dete- 


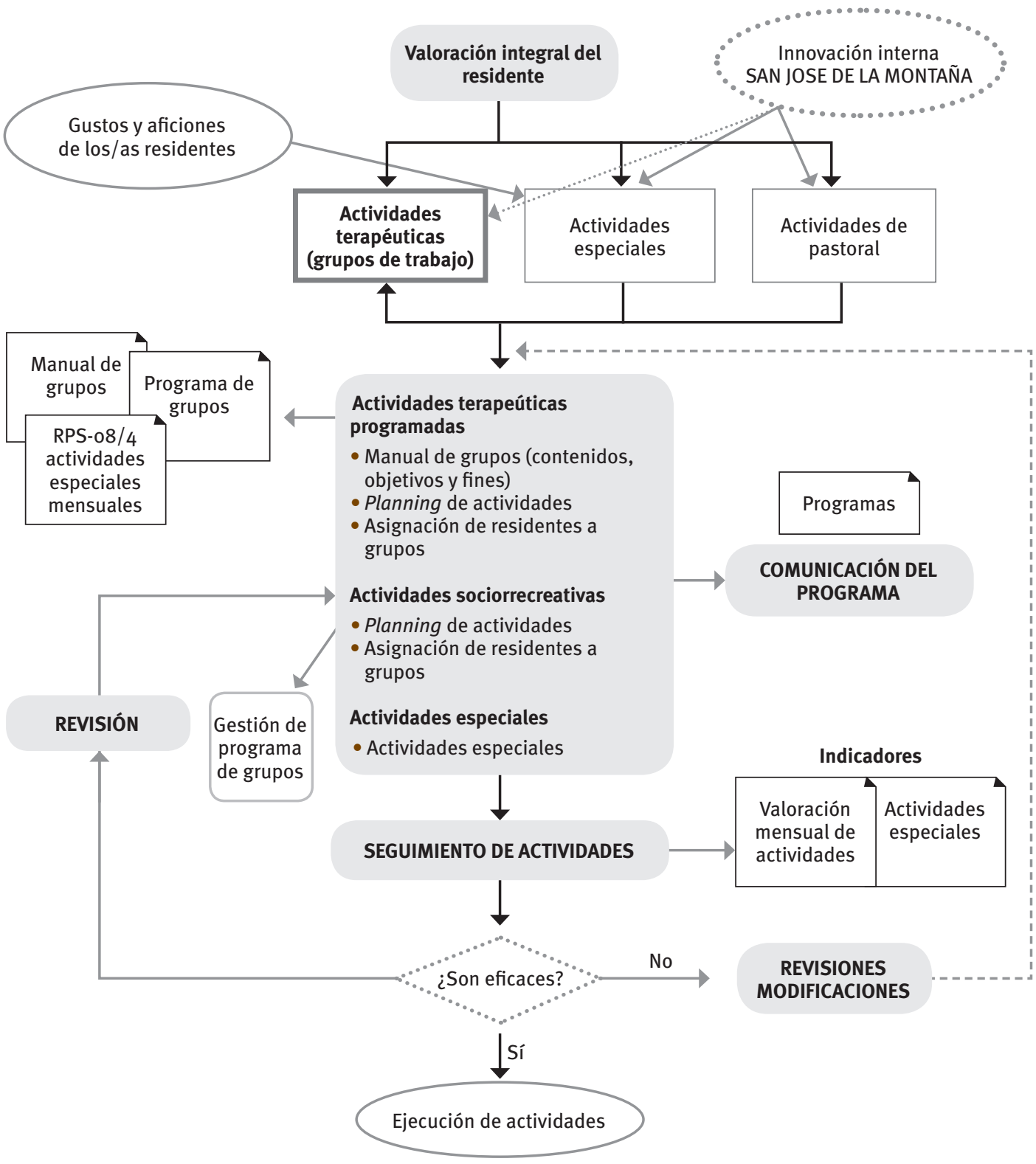

Fuente: Elaboración propia.

rioro. Los diferentes grupos de psicoestimulación se forman en función del grado de deterioro cognitivo, con el objetivo de que sean lo más homogéneos posible y, de esta manera, poder trabajar las diferentes funciones con ejercicios que presenten un grado de dificultad adecuado. En definitiva, no se trata sino de entrenar las capacidades de nuestras y nuestros residentes para que puedan mantener, en la medida de participe en el mantenimiento de los lazos sociales de las personas mayores. Así, la familia, los amigos y, en general, todo su entorno debería proporcionar vínculos afectivos, emocionales y relacionales imprescindibles para la persona y su desenvolvimiento normalizado en la vida del centro. La cantidad y la calidad de los contactos sociales influyen positivamente en el equilibrio integral del residente, además de reforzar áreas como la salud física y psicológica para garantizar su bienestar y una plena calidad de vida.

El contacto con el exterior no debe perderse con el ingreso. Por ello, se potencian programas y actitudes para que el vínculo permanezca. Mediante una serie de registros y aplicaciones informáticas, gestionaríamos los datos recogidos en términos de visitas, 
salidas, actividades de terapia ocupacional, sociorrecreativas, actividades especiales y todas aquellas relacionadas con nuestros distintos grupos de interés. A través de paneles de indicadores específicos, comprobaríamos el cumplimiento de diferentes objetivos en cada uno de los ámbitos definidos. El análisis de los datos ofrecería información para adecuar o detectar nuevos recursos comunitarios al servicio de aquellos residentes con un nivel de interactividad exterior significativamente bajo.

\subsection{Manual de grupos y herramientas de gestión de los mismos}

Como entidad certificada en las normas ISO 9001 y UNE 158101, la residencia San José de la Montaña cuenta con un procedimiento específico que describe, regula y gestiona el conjunto de actividades grupales del geriátrico. El manual de grupos diferencia entre actividades programadas y actividades especiales. Las primeras se distinguen por presentar un enfoque práctico, activo y de interrelación, y se clasifican en dos grupos:

- Terapia ocupacional: lúdicas (bingo, ajedrez, cartas, dominó, etc.), intelectuales (lectoescritura, puzles, música, biografías, etc.) y de destreza manual.

- Sociedad: normalmente, giran en torno a la cultura cotidiana, la memoria cultural y los valores sociales.

Dicho manual define, para cada una de ellas, sus objetivos y tareas. No obstante y entre otros retos, este proyecto aspira a explotar el conjunto de registros implícitos en el procedimiento conforme al uso de herramientas informáticas de acceso generalizado (básicamente, las propias de Microsoft Office), con el ánimo de medir, o al menos estimar, el éxito de las acciones y medidas implantadas; en otras palabras, trabajar con estándares y/u objetivos que nos permitirán la mejora continua. En este sentido, el diseño de cada indicador/resultado debe contener una serie de alertas que nos permitan una doble actuación:

- Verificar la fiabilidad de los datos y la información introducida (control de la tolerancia del dato registrado, por medio de avisos y formatos predefinidos).

- Si procede, establecer medidas en los casos en que los valores de los indicadores se sitúen fuera de los estándares planificados.

\subsection{Interactividad con los grupos de interés}

A través de los mapas de relaciones y comunicaciones con nuestros grupos de interés, tenemos identificados los agentes sociales que podrían participar del proyecto e, incluso, los canales para lograr la interactividad requerida. No obstante, la clave para una gestión coherente de las oportunidades para facilitar la participación de las personas mayores en la vida de la ciudad pasa por detectar nuevos recursos sociales que interactúen con nuestro centro -incluso compartir agentes sociales con los competidores, mediante la constitución de comisiones, podría ser una opción válida para producir sinergias en este sentido-. La implantación de este proyecto conformaría el embrión sobre el que desarrollar una potencial red de grupos de interés para uso compartido entre geriátricos de proximidad geográfica.

\section{La herramienta contextualizada en programas de estimulación cognitiva}

Probablemente ningún centro asistencial para personas mayores haya llevado a la práctica una experiencia como la presentada. Planteamos esta probabilidad porque a la negativa comunicada por la totalidad de los centros consultados al respecto, habría que añadir la posibilidad de que alguno hubiera trabajado una casuística similar y desconociéramos dicha realidad. Por tanto, la comparación con otras experiencias no es viable y, en consecuencia, tratamos más de exponer un ejercicio teórico que de validar el proyecto mediante diferentes fuentes profesionales $\mathrm{y} / 0$ bibliográficas. En otras palabras, no buscamos sino describir una labor de campo que abarca tres fases diferenciadas: diseño inicial y experiencia piloto (2012), implementación del método (2013) y consolidación mediante la experiencia interna (2014). Si bien el desarrollo de la herramienta en el tiempo ha seguido la secuencia definida en una dinámica de prueba-error-corrección para abordar la exposición de la metodología, en el presente artículo cumpliremos el siguiente itinerario (Figura 2): qué vamos a trabajar con nuestras personas mayores y para qué (ejercicios de psicoestimulación cognitiva), cómo garantizamos que los servicios se prestan y se ajustan a las necesidades específicas de cada residente (valoración cognitiva y registro de valoración mensual de actividades) y cómo la observación diaria contrasta los resultados teóricos de pruebas psicométricas (validación empírica o de campo de las valoraciones cognitivas).

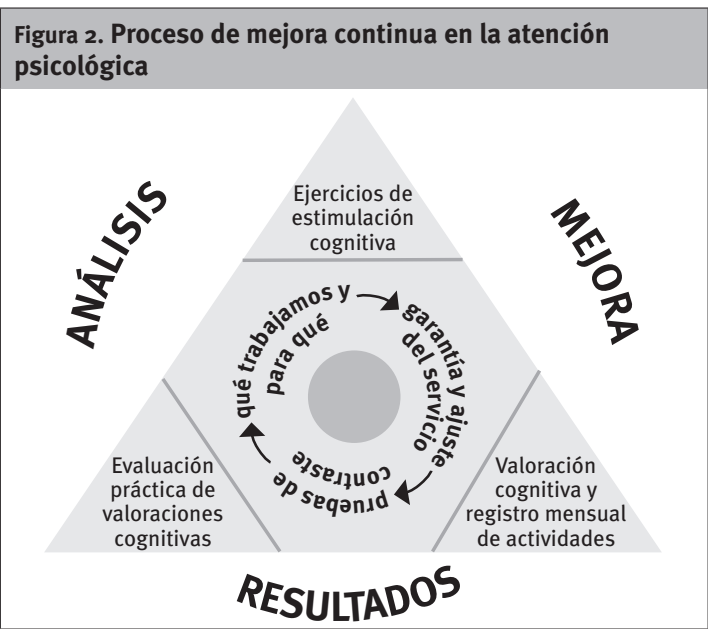

Fuente: Elaboración propia. 


\subsection{Ejercicios de psicoestimulación cognitiva}

Los informes correspondientes a las auditorías internas y externas de las normas ISO 9001 y UNE 158101 evidencian, entre otras cuestiones, que los registros de nuestro centro para gestionar la información recogida en los programas de actividades de psicoestimulación no son del todo adecuados. Concretamente, la sistemática seguida hasta el año 2012 presenta las siguientes ineficacias:

- Los datos registrados no tienen un formato que permita su explotación con el objetivo de detectar personalizadamente las actuaciones en la prestación de los servicios de estimulación cognitiva.

- No es posible valorar la adecuación del directorio de ejercicios de estimulación cognitiva, porque no se han definido medios para registrar la gestión y aplicación del referido directorio.

- Los apuntes sobre las incidencias en la prestación del servicio no constituyen, en ningún caso, episodios de una evolución y, en consecuencia, no facilitan la obtención de comparaciones en el tiempo del perfil neuropsicológico de nuestras personas mayores.

En nuestro geriátrico, la composición de los grupos de psicoestimulación siempre ha estado asociada a los diferentes perfiles neuropsicológicos tratados. Los grupos de psicoestimulación se forman en función del grado de deterioro cognitivo detectado con el Mini-examen Cognitivo de Lobo (MEC), test que forma parte de la evaluación neuropsicológica, con el objetivo de que los grupos sean lo más homogéneos posible y trabajar así las diferentes funciones con ejercicios que presenten un grado de dificultad adecuado. En nuestro centro, se han conformado tres grupos de psicoestimulación cognitiva (G1.1, G1.2 y G2) y un grupo reducido de psicoestimulación (G3), además de actividades individuales.

La diferencia entre estos tres grupos radica principalmente en el nivel de dificultad de las actividades que se proponen para trabajar todas las funciones. Con esta diferenciación se pretende, por un lado, no provocar frustración por no poder realizarlas con éxito; y por otro, evitar que sean demasiado fáciles como para potenciar las aptitudes. Esto incide de manera importante en la motivación de los usuarios que asisten a estas actividades de psicoestimulación, aspecto nada desdeñable a la hora de generalizar las capacidades y habilidades 'entrenadas' a todas las áreas de su vida dentro del centro. La distribución de grupos y perfiles se detalla en el Cuadro 1.

La tabla de actividades de los grupos $\mathrm{G}_{1}$ y $\mathrm{G}_{2}$ es compartida: realizan las mismas actividades, pero con distinto nivel de dificultad. Sin embargo las actividades del grupo reducido (G3) son más simples e incluyen algunas actividades diseñadas ad hoc para algunos de los usuarios. En estas actividades, se trabajan las funciones cognitivas (memoria, ejecutiva, atención, orientación y lenguaje), y se dedica una

\begin{tabular}{|l|l|}
\hline Cuadro 1. Perfil de los grupos de psicoestimulación \\
\hline Grupo & Perfil \\
\hline G1 & Residentes con deterioros leves o moderados \\
\hline G2 & $\begin{array}{l}\text { Residentes con deterioros severos o graves } \\
\text { Residentes con perfiles muy graves y/o con } \\
\text { discapacidades sensoriales que impiden su plena } \\
\text { participación en otros grupos. Trabajan principalmente } \\
\text { en modo de actividad individual, aunque en } \\
\text { determinados casos lo hagan en grupo. }\end{array}$ \\
\hline
\end{tabular}

Fuente: Elaboración propia.

sesión a cada función de manera exclusiva, de forma que al final de la semana se pueda garantizar que se han trabajado las cinco funciones cognitivas.

Este conjunto de actividades, desde la implantación de esta nueva metodología, se somete a control para comprobar la frecuencia en que las mismas se desarrollan y valorar su aceptación, accesibilidad y efectos terapéuticos. En última instancia, el directorio de ejercicios debe ser tal que se garantice la adecuación de los mismos a las necesidades de los residentes, porque, en definitiva, constituyen el entrenamiento necesario para conservar o potenciar las capacidades cognitivas de los residentes con el ánimo de mantener su participación proactiva en el centro para mejorar su calidad de vida.

Con el control continuado del directorio, vamos detectando el grado de uso de cada actividad para valorar su aplicabilidad o, llegado el caso, la querencia a aplicar sólo aquellas cuyo desarrollo es sencillo en detrimento de aquellas otras con mayores dificultades de ejecución. En cierta medida, indirectamente evaluamos el trabajo de nuestras terapeutas ocupacionales en función de los valores observados para variables como frecuencia de aplicación, número de actividades nuevas incorporadas al directorio o número de días con servicios prestados sobre programados. En el Gráfico 1 pueden verse los resultados de esta última variable para los grupos $\mathrm{G}_{1}$ y $\mathrm{G} 2$ durante 2012.

Como se puede observar, salvo para las funciones ejecutiva y orientación en $\mathrm{G} 2$, se ha respetado la programación prevista en el directorio de actividades en un porcentaje considerable. Indudablemente, la realidad de cada grupo (actitudes, aptitudes, motivación, armonía, etc.) condiciona la ejecución de determinadas actividades. Mediante el análisis de los datos, las terapeutas van acomodando la idoneidad de los ejercicios a las capacidades de cada grupo. Una parte de la metodología profundiza en esta cuestión y dota al personal de herramientas específicas con las que tomar decisiones sobre datos contrastados. Como en cualquier otra área de nuestro geriátrico, la adaptabilidad de la aplicación informática diseñada a tal fin es prácticamente permanente, en la medida en que no damos nada por terminado como consecuencia de los axiomas que regulan el ciclo de nuestro sistema integrado de gestión: ningún dato sin análisis, ningún análisis sin conclusión, ninguna conclusión sin acción y ninguna acción sin seguimiento. 


\begin{tabular}{|c|c|c|c|}
\hline \multicolumn{4}{|c|}{$\begin{array}{c}\text { Cuadro 2. Actividades de psicoestimulación organizadas, según funciones y grupos destinatarios } \\
\text { Grupos } 1 \text { y } 2\end{array}$} \\
\hline Función & Ejercicio & Código & Día \\
\hline Memoria & $\begin{array}{l}\text { Recuerdo de textos, palabras o elementos de láminas; verdadero y falso; relacionar fiestas } \\
\text { con lugares; ejercicios de memoria; capitales; recuerdo de personajes famosos o de ficción; } \\
\text { unión de datos distribuidos en columnas; repetición de números o sílabas; categorización; } \\
\text { ¿dónde está el objeto?; recuerdo del pasado (acontecimientos históricos), gentilicios, etc. }\end{array}$ & $\begin{array}{l}101 \text { en } \\
\text { adelante }\end{array}$ & $\begin{array}{l}\text { G1: lunes } \\
\text { G2: miércoles }\end{array}$ \\
\hline Ejecutiva & $\begin{array}{l}\text { Abstracción de similitudes y diferencias, comprensión de efectos de acciones, identificación } \\
\text { de la casualidad, identificación de soluciones, razonamiento, conocimiento cultural, rasgos } \\
\text { semánticos no compartidos, relación lógica de una serie de elementos, completar frases } \\
\text { y expresiones, abstracción de proverbios y frases hechas, solución de problemas, hechos } \\
\text { del pasado y soluciones, ¿cuál sobra?, categorización, preguntas fáciles, preguntas de } \\
\text { comprensión, preguntas generales, refranes, adivinanzas, AVD básicas/instrumentales/ } \\
\text { avanzadas, planificación de acciones complejas, decir nombres de..., decir palabras que } \\
\text { empiecen por..., líos de familia, etc. }\end{array}$ & $\begin{array}{l}201 \text { en } \\
\text { adelante }\end{array}$ & $\begin{array}{l}\text { G1: jueves } \\
\text { G2: viernes }\end{array}$ \\
\hline Atención & $\begin{array}{l}\text { Palabras repetidas, atención selectiva auditiva, fijarse en los errores, buscar los objetos, } \\
\text { contar el número de letras/palabras que cambian, actividades sensoriales, evocación de } \\
\text { colores específicos, agudeza visual, percepción de figuras, reminiscencias visuales, comparar } \\
\text { el número de palabras entre columnas, lectura de números en orden inverso, discriminación } \\
\text { y emparejamiento de figuras, imágenes superpuestas, buscar las siete diferencias, atención } \\
\text { auditiva, características del lugar, juego de bolas, sopa de letras, seguir la serie de colores, } \\
\text { etc. }\end{array}$ & $\begin{array}{l}301 \text { en } \\
\text { adelante }\end{array}$ & $\begin{array}{l}\text { G1: miércoles } \\
\text { G2: jueves }\end{array}$ \\
\hline Orientación & $\begin{array}{l}\text { Desplazamiento en entorno geográfico local, reminiscencia de hechos personales, } \\
\text { orientación temporal, orientación espacial, conocimiento cultural geográfico, conocimiento } \\
\text { semántico y cultural del tiempo, relacionar fiestas con lugares, unir los datos relacionados, } \\
\text { recuerdo de hechos históricos, orientación a la realidad, recorridos, etc. }\end{array}$ & $\begin{array}{l}401 \text { en } \\
\text { adelante }\end{array}$ & $\begin{array}{l}\text { G1: viernes } \\
\text { G2: martes }\end{array}$ \\
\hline Lenguaje & $\begin{array}{l}\text { Completar frases con ayuda, completar frases, comprensión de frases escritas y escuchadas, } \\
\text { ordenar frases, pasar información de uno a otro, sinónimos-antónimos, antónimos, formar } \\
\text { palabras, completar palabras, completar sinónimos, repetición de palabras y frases, dictado } \\
\text { de frases y textos, copia de palabras/frases, lectura de palabras/ frases, lectura de textos, } \\
\text { deletrear, comprensión de textos, ¿a qué te recuerda? (expresión compleja), comprensión- } \\
\text { abstracción, relacionar palabras, emparejar objeto/dibujo con nombre escrito, descripción de } \\
\text { láminas, ejercicios de logopedia (articulación), etc. }\end{array}$ & $\begin{array}{l}501 \text { en } \\
\text { adelante }\end{array}$ & $\begin{array}{l}\text { G1: martes } \\
\text { G2: lunes }\end{array}$ \\
\hline \multicolumn{4}{|c|}{ Grupo 3} \\
\hline Todas & $\begin{array}{l}\text { Orientación en tiempo y espacio, orientación en persona, fiestas-lugares-fechas, recuerdos, } \\
\text { personajes famosos, partes del cuerpo, denominar/repetir objetos, denominar/repetir } \\
\text { colores, denominar/repetir formas, denominar/repetir palabras/letras, denominar/repetir } \\
\text { números, denominar/repetir días de la semana/meses, uso de objetos, puzles, cubo de } \\
\text { colores, piezas de madera, juego de pelota, lectura, escritura, juego del reloj, secuencias } \\
\text { de AVD básicas, refranes, completar frases y expresiones, identificación de la casualidad, } \\
\text { comprensión de efectos y acciones, etc. }\end{array}$ & $\begin{array}{l}1 \text { en } \\
\text { adelante }\end{array}$ & $\begin{array}{l}\text { Personalizada } \\
\text { para cada } \\
\text { residente }\end{array}$ \\
\hline
\end{tabular}

AVD: actividades de la vida diaria.

Fuente: Elaboración propia.

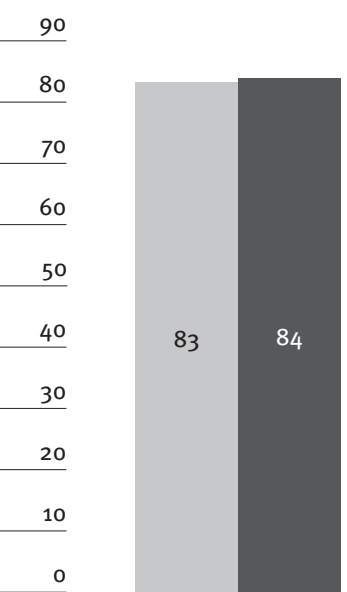

Memoria

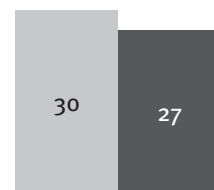

Ejecutiva

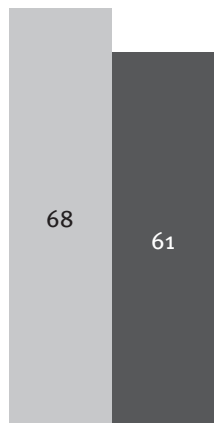

Atención

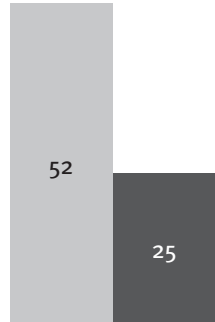

Orientación

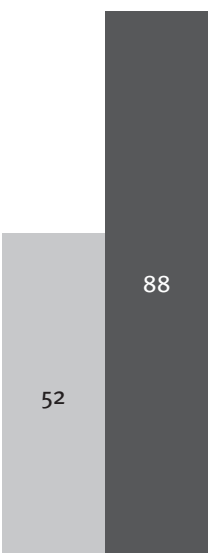

Lenguaje

G1

$\mathrm{G} 2$

Fuente: Elaboración propia. 


\subsection{Valoración cognitiva y registro mensual de actividades}

\subsubsection{Valoración cognitiva}

Parte del trabajo del área de atención psicológica consiste en valorar semestralmente y de una manera estandarizada el estado cognitivo de todos los residentes. Se entiende por funciones cognitivas el rendimiento intelectivo de la persona, el cual consta de diferentes áreas, que se pueden clasificar en cinco funciones principales: memoria, atención/percepción, lenguaje, orientación y funciones ejecutivas.

La valoración se inicia con un test de cribado (Miniexamen Cognitivo de Lobo). Una vez detectada la existencia de deterioro, se evalúa en qué grado y funciones se presenta éste, realizando una evaluación más exhaustiva con pruebas escogidas de diferentes baterías:

- Test Barcelona (versión abreviada del Test Barcelona-R, 2005) [Peña Casanova et al., 1997]: explora todas las áreas cognitivas y ofrece un perfil cognitivo de la persona, con sus puntos fuertes y débiles.

- Test de Vocabulario de Boston (BNT).

- Test de Boston para la Evaluación de la Afasia (BDAE).

- Test de Copia y de Reproducción de Memoria de Figuras Geométricas Complejas (Rey).

Esta medición psicométrica forma parte de una valoración integral RAl practicada con cada ingreso, y que se repite con frecuencia anual y seguimientos semestrales. Dicha valoración es responsabilidad de un equipo multidisciplinar, compuesto por los responsables de las diferentes áreas de atención directa. En su despliegue, lleva asociada unos objetivos que el equipo se marca con cada persona usuaria del centro, bien por área o bien de manera interdisciplinar, y que finalmente componen el plan de atención individualizada (PAI). En el caso del área psicológica, la consecución de ese objetivo depende en gran medida de las actividades de psicoestimulación que se realizan de una manera sistemática y regular a lo largo de la semana.

\subsubsection{Registro de actividades: control de datos y explotación de la información}

Si bien es evidente que nuestro centro se ha preocupado en registrar, no lo ha hecho con un sentido concreto. Para corregir esta ineficacia, el servicio psicosocial de San José de la Montaña redacta un proyecto de mejora al respecto, en el que participan la psicóloga y las terapeutas ocupacionales, que define aquellas acciones encaminadas al diseño de un registro que posibilite responder de las necesidades planteadas (Figura 3). Con este nuevo enfoque, la introducción de datos está sometida a control, garantizándose su bondad para una rigurosa explotación de los mismos. El sistema basa todo su potencial en el contraste permanente de los datos y el cumplimiento de los niveles de tolerancia para los mismos. Si un dato no respeta las condiciones de entrada, la herramienta determina qué incumplimientos se dan, para proceder a su corrección. Obvia decir que este tipo de controles se desarrollan mediante una programación informática específica, basada en cualquier herramienta estándar que ofrece el mercado; en nuestro caso, por intuitiva y gráfica, decidimos que la hoja de cálculo Excel, de Microsoft, reúne las características suficientes para ajustarse a nuestros requerimientos.

Como ya recoge el directorio de ejercicios (Cuadro 2), cada día de la semana se actúa sobre una función cognitiva determinada. Por su parte, cada mes deben relacionarse los integrantes activos (y no otros) de cada grupo. Obtener estos registros mensuales de manera automática significa que la propia herramienta debe filtrar y cumplir todas las condiciones para facilitar el trabajo de registro por parte de las terapeutas, y el de supervisión a cargo de la psicóloga. En otras palabras, no estamos ante un impreso que tengamos que cumplimentar casi de forma artesanal y manuscrita, sino, por el contrario, ante un documento dinámico que ajusta su información al mes en cuestión y que, además, se convierte en una base de datos con la que poder operar para obtener cuantas salidas de información queramos definir. El horizonte de gestión que se abre con este enfoque bien merece el esfuerzo empleado en el diseño de la herramienta.

No debemos olvidar que buscamos aplicar un método integrado. El registro es el documento donde volcar datos conforme a criterios consensuados para un determinado colectivo de personas que previamente debemos identificar. Una primera base de datos gestionará qué residentes configuran cada uno de los grupos de psicoestimulación, durante cuánto tiempo, con qué frecuencia y con qué compatibilidad (nuevamente asoma la idea de control para asegurar que el registro de la información cumple con las condiciones debidas). En función de las puntuaciones psicométricas obtenidas por cada residente (dos valoraciones anuales, con periodicidad semestral), la psicóloga del centro configura los grupos, y los registros mensuales reaccionan automáticamente a cada cambio de distribución. Incluso antes de proceder a la impresión de los nuevos grupos para conocimiento de las terapeutas ocupacionales, una serie de alarmas nos avisarán de la correcta configuración de los mismos, con objeto de cumplir que nadie esté presente en actividades excluyentes (por ejemplo, en $\mathrm{G}_{1}$ y $\mathrm{G}_{2}$ simultáneamente). Estamos en disposición de facilitar los registros mensuales para que las terapeutas vayan apuntando diariamente los ejercicios desplegados o las causas que han impedido su ejecución.

Nuestra metodología aspira a automatizar al máximo el cálculo de cuantas variables se manejen. Cualquier salida de información, cualquiera que sea el formato (listados, gráficos, paneles de indicadores, etc.) deberá ser obtenida como consecuencia de los 
Objetivo: que un mínimo del $75 \%$ del grupo acuda, al menos, al $75 \%$ de las actividades.

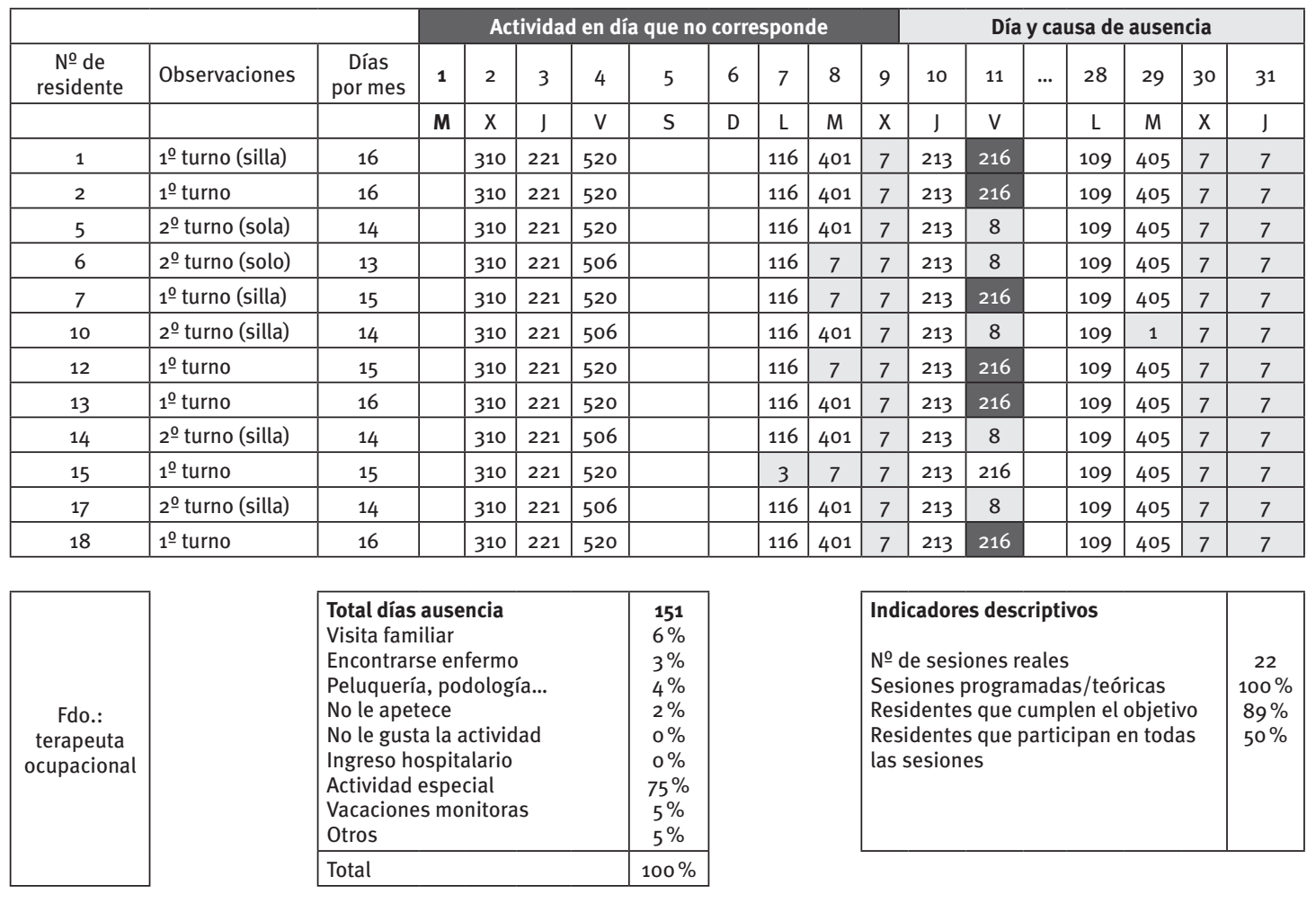

Fuente: Elaboración propia.

correspondientes procesos informáticos y siempre bajo los criterios establecidos por profesionales competentes.

\subsubsection{Control en la introducción de datos}

El control en la introducción de datos resulta fundamental e imprescindible para garantizar que el seguimiento personalizado se ajusta a programa y no está 'contaminado' por valores fuera de rango o tolerancia. Es la parte del sistema encargada de autenticar la bondad del dato y, en consecuencia, de garantizar la explotación de la información. El Cuadro 3 detalla con algunos ejemplos el contenido de este control que, visualmente, se activa con diferentes colores.

\subsubsection{Explotación de la información}

Una vez contrastado el dato, lo analizaremos desde una doble perspectiva: individual, para determinar el nivel de servicios prestados a cada residente; y grupal, para el seguimiento de indicadores en el cuadro de mando.

Respecto de la primera, a través de diferentes tablas dinámicas, obtenemos información acumulada, o de un mes en concreto, de los ejercicios que ha realizado y qué días, su frecuencia, el porcentaje de parti-

\begin{tabular}{|c|c|c|}
\hline \multicolumn{3}{|c|}{$\begin{array}{l}\text { Cuadro 3. Código de colores empleado para el control de } \\
\text { los datos introducidos en el registro de actividades }\end{array}$} \\
\hline Color & Aviso & Ejemplos \\
\hline Rojo & $\begin{array}{l}\text { Error por falta o } \\
\text { incoherencia de } \\
\text { dato respecto a los } \\
\text { criterios fijados }\end{array}$ & $\begin{array}{l}\text { - Día de actividad sin registrar } \\
\text { - Información registrada para días } \\
\text { sin actividad programada } \\
\text { - Código de actividad inexistente } \\
\text { - Ejercicios asignados a residentes } \\
\text { no existentes o pertenecientes a } \\
\text { otros grupos }\end{array}$ \\
\hline Verde & $\begin{array}{l}\text { Actividades fuera } \\
\text { de programación }\end{array}$ & $\begin{array}{l}\text { - Actividad registrada y correspon- } \\
\text { diente a otro día }\end{array}$ \\
\hline Azul & Día sin ejercicio & $\begin{array}{l}\text { - Día de actividad especial a la que } \\
\text { acude el residente } \\
\text { - Día sin ejercicio por diferentes } \\
\text { causas (ingreso hospitalario, } \\
\text { enfermedad, visita familiar, etc.) }\end{array}$ \\
\hline
\end{tabular}

Fuente: Elaboración propia.

cipación (número de ejercicios realizados sobre programados) y la distribución porcentual de causas de ausencia. Esta última descriptiva es especialmente significativa, pues si la no realización de las actividades se debe a causas como 'visita familiar', 'no apetece/no gusta' o 'peluquería/podología’, podría plantear cambios en la organización de la atención al residente 0 , incluso, de su entorno sociofamiliar al objeto de maximizar los efectos beneficiosos de este tipo de terapias cognitivas. Veamos, en el ejemplo de la Figura 4, qué información se obtiene. 
Porcentajes participación y distribución ausencias (estimulación cognitiva-G1)

\begin{tabular}{lcl}
\hline $\begin{array}{l}\text { Selección de variables } \\
\text { - } n^{\circ} \text { mes }(0 \text {-año) }\end{array}$ & 4 & Abril \\
- Residente & 2153 & XXXXX XXXXXX, XXXXX
\end{tabular}

27? : revisar registro mensual por considerable probabilidad de anotación incorrecta (actualizer activando "I")

\begin{tabular}{|c|c|c|c|c|c|}
\hline$n^{\circ}$ mes/periodo & Nombre & $\%$ participación & $\%$ ausencia & $\%$ & Tipo \\
\hline \multirow[t]{4}{*}{ Abril } & \multirow[t]{4}{*}{ 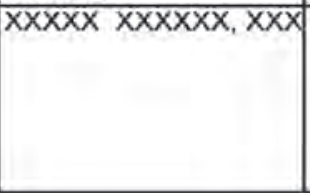 } & \multirow[t]{4}{*}{78,57} & \multirow[t]{4}{*}{21,43} & & \\
\hline & & & & 37.50 & Actividad especial \\
\hline & & & & 25,00 & Ajustes vacaciones \\
\hline & & & & 12,50 & $\begin{array}{l}\text { No le apetece/no le gusta } \\
\text { Actividad religiosa } \\
\text { Visita familiar }\end{array}$ \\
\hline
\end{tabular}

Listado de ejercicios aplicados por función (estimulación cognitiva-G1)

\begin{tabular}{|c|c|c|c|}
\hline \multicolumn{4}{|c|}{$\begin{array}{l}\text { Selección de variables } \\
n^{\circ} \text { mes }(0 \text {-año) }\end{array}$} \\
\hline \multicolumn{4}{|c|}{ (actualizar activando "I") } \\
\hline $\mathrm{n}^{\circ} \mathrm{mes} / \mathrm{periodo}$ & Nombre & Código Ejercicio & Dia \\
\hline \multirow[t]{11}{*}{ Abril } & \multirow[t]{11}{*}{$x \times x x x \quad x x x x x x, x x x$} & 113 Categorizar & 14 \\
\hline & & 115 Recordando el pasado, acontecimientos históricos & 28 \\
\hline & & \begin{tabular}{l|l}
205 & Razonamiento conocimiento cultural \\
\end{tabular} & 24 \\
\hline & & 213 Categorización & 3 \\
\hline & & 215 Preguntas de comprensión & 10 \\
\hline & & 310 Evocación de colores especificos & 16 \\
\hline & & 319 Atención auditiva & 2 \\
\hline & & 403 Orientación temporal & 1 \\
\hline & & 409 Recuerdo de hechos históricos & 15 \\
\hline & & \begin{tabular}{l|l|}
410 & Orientación a la realidad \\
\end{tabular} & 22 \\
\hline & & 518 ¿a qué te recuerda? (expresión compleja) & 4 \\
\hline
\end{tabular}

(actualizar activando "\%")

\begin{tabular}{|l|l|r|}
\hline Función & Ejercicío & Total \\
\hline Atención & Atención auditiva & 1 \\
& Evocación de colores especificos & 1 \\
\hline Total Atención & 2 \\
\hline Ejecutiva & Razonamiento conocimiento cultural & 1 \\
& Categorización & 1 \\
& Preguntas de comprensión & 1 \\
\hline Total Ejecutiva & 3 \\
\hline Lenguaje & ca qué te recuerda? (expresión compleja) & 1 \\
\hline Total Lenguaje & 1 \\
\hline Memoria & Recordando el pasado, acontecimientos históricos & 1 \\
& Categorizar & 1 \\
\hline Total Memoria & 2 \\
\hline Orientación & Orientación a la realidad & 1 \\
& Orientación temporal & 1 \\
& Recuerdo de hechos históricos & 1 \\
\hline Total Orientación & 3 \\
\hline Total general & 11 \\
\hline
\end{tabular}

Fuente: Elaboración propia.

En cuanto a la información grupal se refiere, cada mes se calcula un conjunto de indicadores y se extrae una serie de listados, con diferentes finalidades:

- Seguimiento trimestral del porcentaje de residentes que cumplen las expectativas de participación marcada como objetivo (cuadro de mando) [Gráfico 2].

- Desglose de la no participación (por causas) y evolución gráfica (trimestral y anual) de las mismas, en orden decreciente (Tabla 1).
- Comprobación del cumplimiento de la secuencia de ejercicios prevista en la programación semanal (en otras palabras, que cada día se haga el ejercicio que corresponde y no otro).

- Obtención de indicadores sobre los errores de registro de las terapeutas (Tabla 2), con el ánimo de corregir malos hábitos y exponer positivamente su grado de implicación en el uso y mejora de la herramienta. 


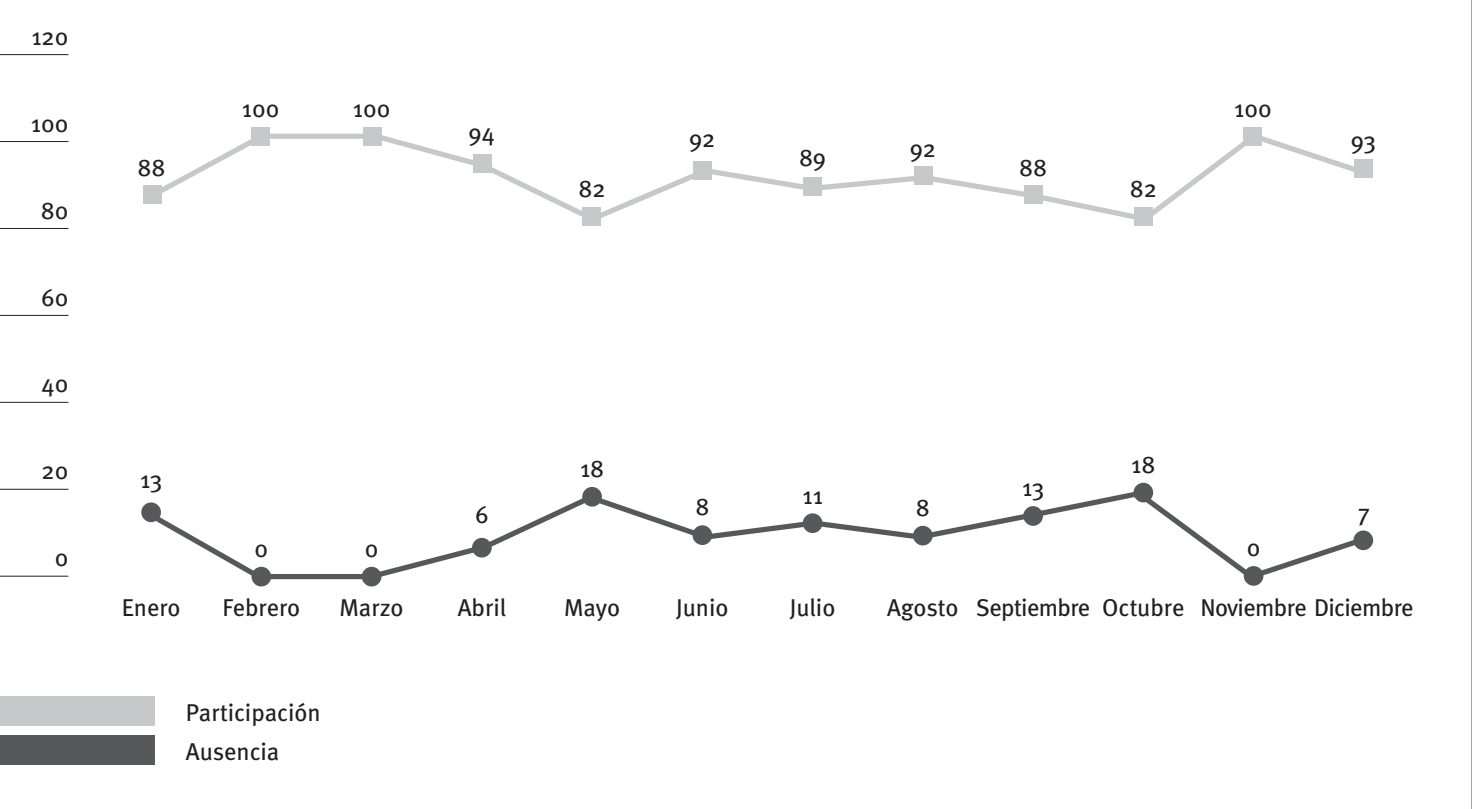

Fuente: Elaboración propia.

Tabla 1. Evolución anual de la no participación en el programa de estimulación cognitiva $(2013, \%)$

\begin{tabular}{|l|c|}
\hline Motivo de la ausencia & $\%$ \\
\hline Actividad especial & 57,03 \\
\hline Otros & 16,31 \\
\hline No le apetece & 8,14 \\
\hline Enfermedad & 5,73 \\
\hline Peluquería, podología, etc. & 5,44 \\
\hline Visita familiar & 3,21 \\
\hline No le gusta la actividad & 2,31 \\
\hline Ingreso hospitalario & 1,79 \\
\hline Vacaciones monitoras & 0,03 \\
\hline Total & 100,00 \\
\hline
\end{tabular}

Fuente: Elaboración propia.

\subsection{Validación empírica o de campo de las valoraciones cognitivas}

En el año 2012 detectamos la necesidad de obtener de manera sistemática y concreta información de la actitud, conducta y rendimiento de los residentes que participaban en cada actividad. Aunque esa información se recogía semestralmente, el registro no establecía categorías descriptivas, no contaba con la posibilidad de comparaciones mensuales o interanuales, ni tampoco indicaba dónde se situaba el residente en relación al grupo. Así, se diseñó una herramienta con campos cerrados, para facilitar el trabajo de registro a las terapeutas. De esta forma, la gestión de los grupos y actividades por
Tabla 2. Distribución mensual de los errores detectados en el registro de información en la base de datos del programa de estimulación cognitiva (2013)

\begin{tabular}{|c|c|c|c|c|c|c|c|}
\hline \multirow{3}{*}{ Mes } & \multirow{3}{*}{$\begin{array}{c}\text { Total } \\
\text { registros }\end{array}$} & \multicolumn{6}{|c|}{ Registros erróneos } \\
\hline & & \multicolumn{2}{|c|}{ Totales } & \multicolumn{2}{|c|}{$\begin{array}{l}\text { En días sin } \\
\text { servicio }\end{array}$} & \multicolumn{2}{|c|}{$\begin{array}{c}\text { En días fuera } \\
\text { pauta }\end{array}$} \\
\hline & & $n$ & $\%$ & $n$ & $\%$ & $n$ & $\%$ \\
\hline Ene & 336 & 0 & 0,0 & 0 & 0,0 & 0 & 0,0 \\
\hline Feb & 380 & 0 & 0,0 & 0 & 0,0 & 0 & 0,0 \\
\hline Mar & 324 & 3 & 0,9 & 2 & 66,7 & 1 & 33,3 \\
\hline $\mathrm{Abr}$ & 378 & 0 & 0,0 & 0 & 0,0 & 0 & 0,0 \\
\hline May & 374 & 0 & 0,0 & 0 & 0,0 & 0 & 0,0 \\
\hline Jun & 357 & 0 & 0,0 & 0 & 0,0 & 0 & 0,0 \\
\hline Jul & 399 & 8 & 2,0 & 4 & 50,0 & 4 & 50,0 \\
\hline Ago & 378 & 0 & 0,0 & 0 & 0,0 & 0 & 0,0 \\
\hline Sep & 357 & 8 & 2,2 & 8 & 100,0 & 0 & 0,0 \\
\hline Oct & 352 & 0 & 0,0 & 0 & 0,0 & 0 & 0,0 \\
\hline Nov & 340 & 0 & 0,0 & 0 & 0,0 & 0 & 0,0 \\
\hline Dic & 340 & 8 & 2,4 & 8 & 100,0 & 0 & 0,0 \\
\hline
\end{tabular}

Fuente: Elaboración propia.

parte de la psicóloga se podría realizar de manera eficiente.

Otro de los beneficios de la herramienta diseñada fue la cuantificación del rendimiento de los usuarios en aquellas actividades en las que participaban, a través de una escala con la que situar empíricamente la ejecución, por parte de cada usuario, de las sesiones de psicoestimulación en un punto $u$ otro, con una frecuencia mensual. De esta manera, conoceríamos el progreso de cada persona y, además, dispondríamos de información relativa al rendimiento de todo el grupo y, por lo tanto, podríamos complementar la información de otros registros utilizados para tomar decisiones en la atención asistencial de cada residente. 


\begin{tabular}{|c|c|c|c|}
\hline \multicolumn{4}{|c|}{ Evaluación cognitiva } \\
\hline Ítems & Ponderación & \multicolumn{2}{|l|}{ Interpretación } \\
\hline \multirow{5}{*}{$\begin{array}{l}\text { - Orientación } \\
\text { - Lenguaje } \\
\text { - Ejecutivas } \\
\text { - Atención } \\
\text { - Memoria }\end{array}$} & 1 = Muy mal & \multicolumn{2}{|c|}{$\begin{array}{l}\text { Incapacidad total para realizar los ejercicios propuestos en cada actividad. No ejecuta correctamente ninguna } \\
\text { tarea propuesta por la terapeuta/monitora. }\end{array}$} \\
\hline & $2=$ Mal & \multicolumn{2}{|c|}{$\begin{array}{l}\text { Capacidad limitada para ejecutar los ejercicios incluidos en las actividades (menos del } 25 \% \text { de todas las tareas } \\
\text { propuestas). }\end{array}$} \\
\hline & $3=$ Regular & \multicolumn{2}{|c|}{$\begin{array}{l}\text { Capaz de realizar bien los ejercicios que proponen las monitoras, pero falla en una cantidad considerable, bien } \\
\text { porque realiza sólo parte del ejercicio, bien porque lo ejecuta mal y la respuesta no es la acertada (al menos } \\
50 \% \text { de las tareas correctamente realizadas). }\end{array}$} \\
\hline & $4=$ Bien & \multicolumn{2}{|c|}{$\begin{array}{l}\text { Capaz de realizar buena parte de las tareas de manera correcta. Falla pocas veces (al menos el } 60 \% \text { de las } \\
\text { tareas realizadas correctamente). }\end{array}$} \\
\hline & $5=$ Muy bien & \multicolumn{2}{|c|}{$\begin{array}{l}\text { Conserva su capacidad en la función en cuestión y presenta un rendimiento óptimo para el potencial de la } \\
\text { persona (una media del } 75-80 \% \text { de ejercicios correctamente realizados). }\end{array}$} \\
\hline \multicolumn{4}{|c|}{ Evaluaciones no cognitivas } \\
\hline Ítems & \multicolumn{2}{|c|}{ Ponderación } & Tipo \\
\hline Participación & \multicolumn{2}{|c|}{$\begin{array}{l}1=\text { No participa } / \text { no asiste } \\
2=\text { Colabora si se insiste } \\
3=\text { Colabora y se implica }\end{array}$} & \\
\hline $\begin{array}{l}\text { Estado de } \\
\text { ánimo }\end{array}$ & \multicolumn{2}{|c|}{$\begin{array}{l}1=\text { Bajo (depresivo) } \\
2=\text { Alto (motivado y enérgico) } \\
3=\text { Ansioso } \\
4=\text { Colérico } \\
5=\text { Apático } \\
6=\text { Otros }\end{array}$} & \\
\hline $\begin{array}{l}\text { Alteraciones } \\
\text { conductuales }\end{array}$ & \multicolumn{2}{|c|}{$\begin{array}{l}1=\text { Frecuentemente }(\geq 8) \\
2=\text { Ocasionalmente }(3-7) \\
3=\text { Puntualmente }(1-2)\end{array}$} & $\begin{array}{l}1=\text { Agresividad verbal } \\
2=\text { Agresividad física } \\
3=\text { Conducta de aislamiento } \\
4=\text { Conducta de demanda } \\
5=\text { Deambulación } \\
6=\text { Otros }\end{array}$ \\
\hline
\end{tabular}

Fuente: Elaboración propia.

Sin género de dudas, ésta es la parte realmente innovadora de la herramienta ${ }^{3}$. Presentarnos como un geriátrico que semestralmente realiza valoraciones cognitivas de sus residentes para ubicarlos en diferentes grupos en función de sus capacidades y que, mediante el mantenimiento o potenciación de las mismas, intentemos maximizar la participación proactiva de nuestros mayores en la vida social interna y externa de nuestro centro no es descubrir nada nuevo. Por mucho que insistamos en transmitir la idea de que todos los procesos de nuestra organización están vinculados y, en consecuencia, nuestra información circula conforme a idénticos criterios de control, rigor y eficiencia, cualquiera que sea el departamento tratado, esta realidad no deja de ser sino una buena práctica que no nos distingue especialmente. Planificar y controlar la gestión de los programas de estimulación cognitiva, terapia ocupacional, y de actividades sociales y recreativas es algo que ya prevé nuestro manual de grupos, como lo haría cualquier otro certificado por la norma ISO 9001. Hacerlo mediante herramientas informáticas que mecanicen al máximo los procesos proyecta una preocupación por producir sinergias que efectivamente nos ayudan a ser eficientes. Pero cuestionar, a través de la observación diaria las mediciones basadas en escalas teóricas -en ocasiones costosas muchos de nuestros residentes- es avalar con datos

${ }^{3}$ La metodología podría extrapolarse a cualquier geriátrico, sea cual fuera su tamaño, ubicación o medios informáticos. Bastaría contar con un técnico en valoración y terapeutas o monitoras ocupacionales, como medios humanos; y un ordenador y un directorio de ejercicio/ actividades, como medios materiales. empíricos los resultados psicométricos y, en caso de nula o dudosa correlación entre ambas, replantear el momento y el producto de la valoración cognitiva. Aquí radica la principal virtud de nuestra metodología, en la medida que no damos por bueno algo que la propia realidad nos ha demostrado que no lo es. Este principio es una versión adaptada de uno de nuestros valores, recogido en el manual de calidad: "afán de superación y compromiso de nuestras personas con la mejora continua".

Como no cabría esperar de otra manera, la percepción de las terapeutas ocupacionales se constituye en el eje sobre el que pivota todo el entramado teórico construido para validar las valoraciones realizadas por la psicóloga conforme a una programación temporal definida. En nuestro centro, las pruebas psicométricas se administran cada seis meses, de acuerdo con el calendario individualizado que consta en la aplicación que gestiona la planificación y seguimiento de las valoraciones RAI. No obstante, como ya hemos explicado, mediante la observación in situ las terapeutas pueden ir ponderando mensualmente aquellos ítems que nos ofrezcan una idea real y cotidiana de la evolución de nuestras personas mayores en sus capacidades cognitivas (funciones), participación, estado de ánimo y alteraciones conductuales. En un registro mensual, y en función de diferentes escalas para cada ítem, las terapeutas irán evaluando el desarrollo de los distintos ejercicios de psicoestimulación para cada residente de cada grupo. Los valores acordados para evaluar tanto el estado cognitivo como la percepción de otros aspectos de interés se detallan en el Cuadro 4. 

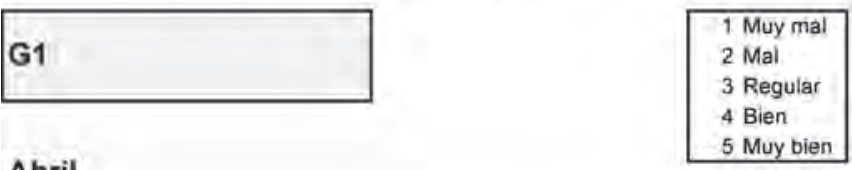

Abril

Evaluación cognitiva

\begin{tabular}{|l|c|c|c|c|c|}
\hline \multirow{2}{*}{ Residente } & \multicolumn{5}{|c|}{ Evaluación cognitiva } \\
\cline { 2 - 6 } & Orientación & Lenguaje & Ejecutivas & Atención & Memoria \\
\hline Residente-1 & 1 Muy mal & 3 Regular & 3 Regular & 2 Mal & 3 Regular \\
\hline Residente-2 & 2 Mal & 4 Bien & 3 Regular & 3 Regular & 3 Regular \\
\hline Residente-3 & 3 Regular & 3 Regular & 2 Mal & 1 Muy mal & 2 Mal \\
\hline Residente-5 & 5 Muy bien & 5 Muy bien & 5 Muy bien & 5 Muy bien & 5 Muy bien \\
\hline Residente-6 & 4 Bien & 5 Muy bien & 5 Muy bien & 4 Bien & 4 Bien \\
\hline Residente-9 & 4 Bien & 4 Bien & 4 Bien & 2 Mal & 4 Bien \\
\hline Residente-15 & 3 Regular & 4 Bien & 4 Bien & 4 Bien & 4 Bien \\
\hline Residente-18 & 2 Mal & 3 Regular & 3 Regular & 2 Mal & 2 Mal \\
\hline evaluación promediada mes-> & 3,39 & 4,17 & 3,78 & 3,39 & 3,83 \\
\hline
\end{tabular}

Evaluación práctica de ítems no cognitivos

\begin{tabular}{|c|c|c|c|c|}
\hline G1 & $\begin{array}{l}1 \text { No participa/no asiste } \\
2 \text { Colabora si se insiste } \\
3 \text { Colabora e implica. }\end{array}$ & $\begin{array}{l}1 \text { Bajo (depresivo) } \\
2 \text { Alto (motivado/energico) } \\
3 \text { Ansioso }\end{array}$ & $\begin{array}{l}1 \text { Frecuentemente } \\
\text { (28) } \\
2 \text { Ocasionalmente }\end{array}$ & $\begin{array}{l}1 \text { Agresividad verbal } \\
2 \text { Agresividad fisica } \\
3 \text { Conducta de aisłamiento }\end{array}$ \\
\hline Abril & & $\begin{array}{l}4 \text { Colérico } \\
5 \text { Apático } \\
6 \text { Otros (observaciones) }\end{array}$ & $\begin{array}{l}\text { (3sns7) } \\
3 \text { Puntualmente } \\
\text { (1sns2) }\end{array}$ & $\begin{array}{l}4 \text { Conducta de demanda } \\
5 \text { Deambulacion } \\
6 \text { Otros }\end{array}$ \\
\hline
\end{tabular}

\begin{tabular}{|c|c|c|c|c|c|c|c|c|c|}
\hline \multirow{2}{*}{ Residente } & \multirow{2}{*}{ Participación } & \multirow{2}{*}{ Estado de ánimo } & \multicolumn{5}{|c|}{ Alteraciones conducta (marcar $n^{\circ}$ ) } & \multirow[b]{2}{*}{ Evolución } & \multirow[b]{2}{*}{ Observaciones } \\
\hline & & & Frecuencia & 12 & 3 & 45 & 56 & & \\
\hline Residente-3 & 1 No participa/no asiste & 6 Otros (observaciones) & $\uparrow$ Frecuentemente & & 3 & & & 2,20 & $\begin{array}{l}\text { Ha estado casi lodo el mes } \\
\text { dormida en la actividad y. } \\
\text { aunque se le llamaba la } \\
\text { atención, volvia a dormirse } \\
\text { Parecia no querer esforzarse }\end{array}$ \\
\hline Residente-5 & 3 Colabora e implica & 6 Otros (observaciones) & & & & & & 5,00 & $\begin{array}{l}\text { Desde la segunda quincena } \\
\text { del mes no ha acudido a la } \\
\text { actividad porque no se }\end{array}$ \\
\hline Residente- 6 & 3 Colabora e implica & 6 Otros (observaciones) & & & & & & 4,40 & $\begin{array}{l}\text { La apatia del mes pasado ha } \\
\text { mejorado un poco y esta de } \\
\text { mejor humor. Aunque cabe } \\
\text { destacar que se le nota algo }\end{array}$ \\
\hline Residente-15 & 3 Colabora e implica & 2 Alto (motivado y enérgico) & & & & & & 3,80 & $\begin{array}{l}\text { Durante la primera quincena } \\
\text { del mes ha estado bastante } \\
\text { animada, pero en la } \\
\text { segunda mitad ha ido } \\
\text { decayendo y no tenía ganas }\end{array}$ \\
\hline Residente-18 & 3 Colabora e implica & 2 Alto (motivado y enérgico) & 3 Puntualmente & & & 4 & & 2.40 & $\begin{array}{l}\text { Este mes be le ha notado } \\
\text { bastante mejor durtante la } \\
\text { actividad. Sus demandas se } \\
\text { han reducido } \\
\text { considerablemente y está } \\
\text { algo más tranquilo y màs } \\
\text { motivado para participar. }\end{array}$ \\
\hline
\end{tabular}

Fuente: Elaboración propia. 
Veamos en un caso real cómo se cumplimenta el registro (Figura 5). Análogamente a lo indicado para el registro mensual de valoraciones, la introducción de datos está sujeta a control: valores fuera de rango, asignación de datos a residentes inexistentes o incompatibilidades de valor se muestran con diferentes colores para proceder a su corrección. En todo caso, distinguiremos entre valoración cognitiva y no cognitiva. La evolución del estado cognitivo del residente se va configurando en función del valor medio alcanzado cada mes, entendido éste como una media aritmética de la ponderación asignada por las terapeutas a cada función cognitiva; por su parte, las variables ‘participación', ‘estado de ánimo’ y ‘alteraciones conductuales’ se analizan por separado, para complementar la información registrada en las evoluciones psicológicas de cada residente y soportar, junto con otros documentos y herramientas (valoración integral RAI, pruebas psicométricas estándar, test SJM, registro de alteraciones de conducta, etc.) los objetivos del plan de atención individualizada.

\subsubsection{Rechazo de la hipótesis nula}

Como se ha comentado, 2012 fue el año del diseño y aplicación de la metodología como experiencia piloto. Antes de seguir avanzando en la construcción del sistema, deberíamos comprobar que nuestra conjetura sobre la correspondencia entre valoración psicométrica y evaluación empírica tiene una base sólida. Realizaremos pruebas de independencia para rechazar la hipótesis nula (variables no asociadas) para un determinado nivel de confianza y con un grado de libertad concreto. Como se demuestra, con los datos agregados para los grupos de psicoestimulación ( $\mathrm{G}_{1}, \mathrm{G}_{2}$ y G3) podemos concluir que existe asociación entre la desviación en la valoración psicométrica (variable 1) y la desviación en la evaluación práctica (variable 2). Si las variables son continuas, el coeficiente de correlación $r$ de Pearson, en sus distin- tas acepciones, es el indicado; si, por el contrario, se trata de atributos divididos en dos o más categorías, el test $\chi^{2}$ y el coeficiente $C$ de contingencia se presentan como alternativas válidas. Este último coeficiente es especialmente aplicable en caso de querer saber si existe o no asociación entre dos conjuntos de categorías pertenecientes a atributos o variables. El Cuadro 5 compara las características diferenciales de ambos coeficientes.

\begin{tabular}{|c|c|}
\hline Coeficiente $\chi^{2}$ & Coeficiente $r$ de Pearson \\
\hline $\begin{array}{l}\text { Afirma si existe o no la } \\
\text { asociación. }\end{array}$ & $\begin{array}{l}\text { Afirma si existe o no relación, y el } \\
\text { grado de tal relación. }\end{array}$ \\
\hline $\begin{array}{l}\text { No indica el sentido de la } \\
\text { asociación. }\end{array}$ & $\begin{array}{l}\text { Indica, positiva o negativamente, } \\
\text { el sentido de la relación. }\end{array}$ \\
\hline $\begin{array}{l}\text { Sirve para variables } \\
\text { nominales, ordinales y de } \\
\text { intervalo. }\end{array}$ & $\begin{array}{l}\text { Sólo sirve para variables de } \\
\text { intervalo. }\end{array}$ \\
\hline $\begin{array}{l}\text { No exige 'distribución } \\
\text { especial' de las variables. }\end{array}$ & $\begin{array}{l}\text { Exige que ambas variables } \\
\text { sigan la curva normal } \\
\text { (homocedasticidad). }\end{array}$ \\
\hline $\begin{array}{l}\text { No exige función especial } \\
\text { entre ambas variables. }\end{array}$ & $\begin{array}{l}\text { Exige función rectilínea lineal } \\
\text { entre las variables. }\end{array}$ \\
\hline
\end{tabular}

Fuente: Elaboración propia.

Analizando las características de una y otra variables estadísticas, y visto que en esta fase preliminar sólo queremos afirmar si existe o no asociación, y no el grado o intensidad en que la misma se produce, optamos por manejarnos con distribuciones de probabilidad $\chi^{2}$. Veamos esta correlación, que contempla, incluso, aquellas valoraciones sin cambios o con desviaciones nulas entre la primera y la segunda (matriz $3 \times 3$; 4 grados de libertad; y un número de observaciones por encima de 50 lo que posibilita el uso del $\chi^{2}$ ) [Figura 6].

Figura 6. Frecuencias reales y teóricas

Matriz de frecuencias reales

\begin{tabular}{|c|c|c|c|c|c|}
\hline & & \multicolumn{3}{|c|}{ Mini-examen Cognitivo de Lobo } & \multirow{2}{*}{ Totales } \\
\hline & & Desviación negativa & Desviación positiva & Desviación nula & \\
\hline \multirow{3}{*}{ Evaluaciones prácticas } & Desviación negativa & 10 & 2 & 5 & 17 \\
\hline & Desviación positiva & 6 & 5 & 4 & 15 \\
\hline & Desviación nula & 5 & 7 & 17 & 29 \\
\hline \multicolumn{2}{|l|}{ Totales } & 21 & 14 & 26 & 61 \\
\hline
\end{tabular}

$$
F_{i j}=\frac{\sum F_{i} \times \sum F_{j}}{N}
$$

Matriz de frecuencias teóricas

\begin{tabular}{|c|c|c|c|c|c|}
\hline & & \multicolumn{3}{|c|}{ Mini-examen Cognitivo de Lobo } & \multirow{2}{*}{ Totales } \\
\hline & & Desviación negativa & Desviación positiva & Desviación nula & \\
\hline \multirow{3}{*}{ Evaluaciones prácticas } & Desviación negativa & 6 & 4 & 7 & 17 \\
\hline & Desviación positiva & 5 & 3 & 7 & 15 \\
\hline & Desviación nula & 10 & 7 & 12 & 29 \\
\hline \multicolumn{2}{|l|}{ Totales } & 21 & 14 & 26 & 61 \\
\hline
\end{tabular}

Fuente: Elaboración propia. 
Sustituyendo valores en la expresión $\chi^{2}=\sum \frac{\left(F_{r} \times F_{t}\right)^{2}}{F_{t}}$, obtenemos que $\chi^{2}=11,64$, un valor superior a 9,49 , es decir, el correspondiente a un nivel de confianza del 0,05 (95\%) y a 4 grados de libertad. En otras palabras, las diferencias entre las frecuencias teóricas y empíricas no se deben al azar ni en un $5 \%$ de las ocasiones. Puede afirmarse, por ejemplo, que la evolución negativa percibida por los terapeutas es consecuencia de un mayor deterioro cognitivo o, a la inversa, que una tendencia a la mejora podría venir como resultado del mantenimiento de las capacidades cognitivas.

\subsubsection{Selección de herramienta de valoración psicométrica}

En el momento en que se plantea hacer un seguimiento a través del tiempo de todos los usuarios de nuestro centro, se piensa en un instrumento de evaluación que, además de medir la existencia de discapacidad cognitiva en diferentes áreas, sirva de referencia para cualquier profesional del sector a la hora de determinar la gravedad del deterioro cognitivo que pueda presentar una persona. Se determina escoger una prueba de las administradas de manera rutinaria en la valoración cognitiva en el centro, con el objetivo de economizar tiempo y tener una aplicabilidad práctica en nuestro día a día.

Tras examinar cada prueba utilizada en nuestra batería neuropsicológica, elegimos el Mini-Mental State Examination (MMSE), desarrollado por Folstein et al. (1975) precisamente para determinar la presencia de deterioro cognitivo en un sujeto y la gravedad de éste en caso de que el test indique la existencia del mismo. En realidad, se utiliza la versión adaptada, MEC, de Lobo et al. (1975), que añade dos ítems al test original, lo que hace subir la puntuación total de 30 a 35 puntos. El umbral para determinar si hay o no deterioro cognitivo es 25 puntos. Con puntuaciones inferiores, se definen intervalos estandarizados para determinar el grado de deterioro cognitivo que presentan en función de la puntuación obtenida. El test ya se utilizaba en el centro como parte de la valoración del área psicológica en el plan de atención individualizada, pero se toma como referencia porque cumple una serie de condiciones:

- Permite realizar un seguimiento a través del tiempo de cada usuario y así conocer su respuesta a las diferentes actividades que se plantean para el mantenimiento de sus capacidades.

- Explora diferentes áreas cognitivas, como la memoria (inmediata y diferida), la orientación en persona y temporoespacial, la atención, las funciones ejecutivas y el lenguaje. Estas mismas áreas se trabajan en diferentes sesiones todas las semanas en las actividades de psicoestimulación.

- El tiempo de aplicación que requiere es relativamente corto, de unos diez minutos.
- Está recomendado por la American Geriatric Society como instrumento de evaluación cognitiva para la población geriátrica.

\subsubsection{Evaluaciones prácticas: tendencias e índice de correlación}

Mientras el residente esté activo en un grupo, dispondremos de tantos datos a analizar como el producto del número de meses por las cinco funciones cognitivas. Como las pruebas psicométricas proyectan una imagen global del perfil cognitivo, la evaluación práctica que debe validarlas debe hacer lo mismo. Por tanto, si bien la herramienta ofrece resultados particularizados en cada función que pudieran plantear cambios en los ejercicios de psicoestimulación, nuestro principal cometido es contrastar la valoración teórica desde una perspectiva integral. Como en toda apreciación personal, es difícil evitar cierto grado de subjetividad en las ponderaciones, a pesar de las instrucciones que, de hecho, se emiten en sentido contrario. No obstante, nuestra experiencia demuestra que el sesgo debido a esta circunstancia apenas tiene incidencia negativa, por cuanto que, como más adelante se explica, la percepción de las terapeutas corrobora en muchos casos la medición psicométrica de la psicóloga.

El problema de la determinación de tendencias pasa por resolver previamente qué tipo de correlación existe entre las variables manejadas (número de mes y ponderación). Con sus particularidades, la predicción de valores, conocidas las puntuaciones otorgadas por las terapeutas conforme van sucediéndose los meses, no consiste sino en encontrar una función $Y=f(t)$ ajustada con la máxima aproximación mediante el método de los mínimos cuadrados. Si la observación empírica no es coincidente con la psicométrica para un determinado mes, la estimación de valores mediante rectas de regresión lineal pueden darnos una imagen ciertamente fiel de la evolución experimentada por el residente. El grado de fidelidad dependerá de la consistencia de la regresión o, en otros términos, del valor absoluto alcanzado por el coeficiente de correlación $r$ de Pearson. Se desprecian otros coeficientes por considerar que el empeoramiento o mejora del estado cognitivo evoluciona de forma constante a la velocidad que indica la pendiente de la recta $Y=a+b X$, y no a distintas velocidades, como podrían indicar otras funciones (parábolas, hipérbolas, exponenciales, etc.). En concreto, las categorías para determinar la solidez de la correlación se recogen en el Cuadro 6.

El escenario es el siguiente: valoraciones psicométricas con o sin evaluaciones prácticas que, en caso negativo, podrían ser estimadas mediante una recta de regresión. Según sea cada caso, dispondremos de toda la información o de una parte. Ya hemos indicado que en la residencia San José de la Montaña se realizan dos valoraciones MEC al año, con un intervalo de seis meses entre ambas. Lógicamente, la comparativa entre las puntuaciones obtenidas puede 


\begin{tabular}{|c|c|l|}
\hline \multicolumn{3}{|l|}{ Cuadro 6. Intervalos de interpretación de la $r$ de Pearson } \\
\hline Valor & Grupo & Interpretación \\
\hline$-1,00$ & 1 & Siempre a peor \\
\hline$[-0,99,-0,90]$ & 2 & A peor, con correlación muy alta \\
\hline$[-0,89,-0,70]$ & 3 & A peor, con correlación alta \\
\hline$[-0,69,-0,40]$ & 4 & A peor, con correlación moderada \\
\hline$[-0,39,-0,20]$ & 5 & A peor, con correlación baja \\
\hline$[-0,19,-0,01]$ & 6 & A peor, con correlación muy baja \\
\hline 0,00 & 7 & Sin tendencia \\
\hline$[0,01,0,19]$ & 8 & A mejor, con correlación muy baja \\
\hline$[0,20,0,39]$ & 9 & A mejor, con correlación baja \\
\hline$[0,40,0,69]$ & 10 & A mejor, con correlación moderada \\
\hline$[0,70,0,89]$ & 11 & A mejor, con correlación alta \\
\hline$[0,90,0,99]$ & 12 & A mejor, con correlación muy alta \\
\hline 1,00 & 13 & Siempre a mejor \\
\hline
\end{tabular}

Fuente: Calvo (1990).

producir desviaciones positivas (mayor puntuación en la segunda valoración que en la primera), negativas (menor) o nulas (igual). Mediante el análisis de la percepción de las terapeutas, trataremos de definir un patrón acorde a un conjunto de preceptos que permitan sistematizar la evaluación práctica de la valoración psicométrica. El modelo planteado realiza una comparación escalonada en dos niveles:

- Nivel 1: confrontar las desviaciones de los MEC y las de las ponderaciones de las terapeutas para determinar, en función de criterios predefinidos, la correspondencia entre unas y otras.

- Nivel 2: si el nivel anterior no muestra conexión entre las desviaciones o no existe alguna evalua- ción práctica (por ejemplo, cuando el alta en un grupo es posterior a la primera valoración psicométrica, o la baja es anterior a la segunda), mediante el análisis de tendencias basadas en coeficientes de correlación podríamos interpretar, si concurrieran las condiciones necesarias para ello, que la valoración empírica de las terapeutas ratifica la medición psicométrica de la psicóloga. La limitación temporal de observaciones (no más de doce al año) aconseja considerar que las líneas de tendencia son significativas a partir del cumplimiento de las siguientes premisas:

- Tres o más meses de actividad.

- No más de tres meses entre la fecha de la valoración cognitiva y el último mes de actividad (las series temporales no deberían estar muy alejadas en el tiempo si se pretende evaluar mediante la observación empírica los resultados de un test psicométrico).

- Valores absolutos del coeficiente de correlación $r$ de Pearson superiores a un valor absoluto de 0,4 .

Alguien podría interpretar que el modelo no es ambicioso si consideramos el valor relativamente bajo exigido al coeficiente. No obstante, dado que la comparativa debe ser entendida en términos de signo (tendencia positiva o negativa) y no de aproximaciones hasta rozar la igualdad entre predicción y realidad, consideramos que técnicamente el umbral está justificado. En el Cuadro 7 se detallan las diferentes combinaciones entre MEC, evaluaciones prácticas y líneas de tendencia que sustentan la correspondencia entre las valoraciones teóricas o psicométricas, y prácticas o empíricas.

\begin{tabular}{|c|c|c|c|}
\hline \multicolumn{4}{|c|}{ Cuadro 7. Casuística e interpretación } \\
\hline \multicolumn{2}{|c|}{ Valoración cualitativa } & \multicolumn{2}{|c|}{ Criterios para validar los códigos } \\
\hline Código & Concepto & Código & Criterios \\
\hline 1 & La EP valida el MEC & \multirow{4}{*}{1} & MEC positivo, EP positiva, tendencia no considerable \\
\hline 2 & Falta la EP, pero la tendencia valida el MEC & & MEC negativo, EP negativa, tendencia no considerable \\
\hline 3 & Las EP no valida el MEC, pero la tendencia sí & & MEC con variación absoluta < 5 , EP nula, tendencia no considerable \\
\hline 4 & La EP no valida el MEC y no hay tendencia & & MEC nulo, EP con desviación < 5/35, tendencia no considerable \\
\hline 5 & Falta la EP y la tendencia no valida el MEC & \multirow{3}{*}{2} & MEC positivo, no EP, tendencia positiva, $r>0,4$ \\
\hline 6 & Ni la EP ni la tendencia validan el MEC & & MEC negativo, no EP, tendencia negativa, $r>0,4$ \\
\hline 7 & Sin datos para estimar tendencias & & MEC con variación absoluta < 5 , no EP, tendencia nula $(r=0)$ \\
\hline \multirow{13}{*}{8} & \multirow{13}{*}{ No considerable como objetivo } & \multirow{4}{*}{3} & MEC positivo, EP negativa, tendencia positiva, $r>0,4$ \\
\hline & & & MEC negativo, EP positiva, tendencia negativa, $r>0,4$ \\
\hline & & & MEC con variación positiva < 5 , EP negativa, tendencia nula \\
\hline & & & MEC con variación negativa < 5 , EP positiva, tendencia nula \\
\hline & & \multirow{2}{*}{4} & MEC positivo, EP negativa, no tendencia \\
\hline & & & MEC negativo, EP positiva, no tendencia \\
\hline & & \multirow{3}{*}{5} & MEC positivo, no EP, tendencia negativa, $r>0,4$ \\
\hline & & & MEC negativo, no EP, tendencia positiva, $r>0,4$ \\
\hline & & & MEC con variación absoluta $\geq 5$, no EP, tendencia nula \\
\hline & & \multirow{4}{*}{6} & MEC positivo $\geq 5$, EP negativa o nula, tendencia negativa o nula \\
\hline & & & MEC negativo $\leq 5$, EP positiva o nula, tendencia positiva o nula \\
\hline & & & MEC con variación absoluta $\geq 5$, EP nula, tendencia nula \\
\hline & & & MEC nulo, EP con desviación absoluta $\geq$ a 5/35, tendencia no nula \\
\hline
\end{tabular}

EP: evaluación práctica. MEC: Mini-examen Cognitivo de Lobo. r: coeficiente de correlación de Pearson.

Fuente: Elaboración propia. 
4.3.4. Ejemplos: sin validación y validaciones mediante evaluaciones prácticas o líneas de tendencia

Utilizando un ejemplo por caso, intentaremos ilustrar cómo se traduce en la práctica este conjunto de condiciones, criterios, programación informática y análisis de datos cuantitativos y cualitativos:

- Caso 1: mejoría en la puntuación del MEC que, sin embargo, no tiene refrendo mediante la evaluación práctica.

- Caso 2: valoración del MEC que indica una mejora en el estado cognitivo que las terapeutas ocupacionales también han observado en momentos coincidentes con las valoraciones psicométricas.

- Caso 3: valoraciones teóricas y prácticas no coincidentes y que, no obstante, se ve ratificada por la tendencia correspondiente a las observaciones empíricas de los últimos meses.

No podemos olvidar que la construcción de la herramienta debe resolver el extenso abanico de casuísticas que la realidad presenta. La propia dinámica en la gestión de cualquier actividad del manual de grupos de la residencia San José de la Montaña explica que no siempre dispongamos de la totalidad de la información necesaria para comparar teoría y práctica. Eventualidades como la inexistencia de valoración psicométrica o práctica, la insuficiencia del número de meses de actividad, los coeficientes de correlación con baja consistencia o la participación en actividades excesivamente alejadas en el tiempo no deberían suponer problemas de interpretación ni obstáculos para el desarrollo del sistema planteado. Huelga decir que detrás de la resolución de este tipo de incidencias hay buenas dosis de programación informática que intentan limitar la introducción de datos a lo estrictamente esencial, de manera que la colección de listados, indicadores, gráficos, etc. sean consecuencia de los cálculos implícitos en el proceso y no de elaboraciones manuales más o menos acertadas. Como es lógico, no es objeto de este artículo describir todo el procedimiento técnico que subyace a la herramienta, si bien entendemos justificado este comentario por transmitir una idea de rigor basada en criterios y planteamientos lo más científicos posibles.

Presentemos el funcionamiento de la herramienta para los tres casos definidos. El patrón de cálculo debe ser capaz de solventar cualquier eventualidad para que el método no ofrezca resultados incoherentes o procesos irresolubles. Para cada residente de cada grupo, desplegaremos su información mensual, modificándola y adaptándola hasta precisar con qué criterios se validan o no las pruebas psicométricas. En esta fase, factores como la imaginación, la creatividad y un nivel aceptable de audacia son aliados más que aconsejables, y, en todo caso, siempre están presentes en cualquier proyecto innovador. La Figura 7 detalla cómo se ha estructurado la información, y su explotación para nuestros ejemplos (residente $4=$ caso 1 ; residente $6=$ caso 2 ; y residente $13=$ caso 3 ).

Dado que la complejidad implícita en el diseño de la herramienta aconseja proteger ésta, los usuarios visualizarán exclusivamente aquellas áreas con información relevante para aquéllos, ocultando los procesos de cálculo y restringiendo los permisos de acceso a las personas autorizadas para realizar los cambios pertinentes. Pero nuestro ánimo protector no termina en vigilar el uso de la herramienta; a un mayor nivel de cuidado se encuentra la progresiva implantación de métodos ágiles, fiables y adaptables que mejoren los resultados de nuestros

Figura 7. Ejemplos de evaluaciones prácticas: valoración, interpretación y cumplimiento de objetivos

Objetivo: que, de los/as residentes con 2 valoraciones MEC, al menos un $75 \%$ lo tengan validado, cualitativamente, por EP o po tendencia para diferencias absolutas en valoraciones MEC iguales o superiores a o puntos en términos absolutos

\begin{tabular}{|c|c|c|c|c|c|c|c|c|c|c|c|c|c|}
\hline \multirow{4}{*}{ Residente } & \multicolumn{5}{|c|}{ Valoración MEC } & \multicolumn{8}{|c|}{ Correlación MEC y evaluaciones prácticas o tendencias } \\
\hline & \multirow{2}{*}{\multicolumn{2}{|c|}{ Fechas }} & \multirow{2}{*}{\multicolumn{3}{|c|}{ Puntuación MEC }} & \multirow{2}{*}{\multicolumn{3}{|c|}{ Evaluaciones prácticas }} & \multicolumn{5}{|c|}{$\begin{array}{c}\text { Tendencia } \\
\text { (si no EP: } \mathrm{n}<3 \text {, dist }>3 \text { y abs }(r)>0,4)\end{array}$} \\
\hline & & & & & & & & & \multicolumn{3}{|c|}{ Tendencia } & \multicolumn{2}{|c|}{ Datos tendencia } \\
\hline & $1^{\underline{a}}$ & $2^{\mathrm{a}}$ & $1^{\underline{a}}$ & $2^{\mathrm{a}}$ & $\Delta(\%)$ & $1^{\underline{a}}$ & $2^{\mathrm{a}}$ & $\Delta(\%)$ & $1^{\underline{a}}$ & $2^{\mathrm{a}}$ & $\Delta(\%)$ & meses & r Pearson \\
\hline Residente 4 (caso 1) & $24-04$ & $23-10$ & 18 & 23 & 28 & 3,60 & 3,60 & 0,00 & 3,60 & 3,60 & 0,00 & 12 & 0,00 \\
\hline Residente 6 (caso 2) & $05-06$ & $18-12$ & 32 & 34 & 6 & 4,40 & 4,60 & 5,00 & 4,49 & 4,65 & 4,00 & 12 & 0,87 \\
\hline Residente 13 (caso 3) & 09-01 & $17-07$ & 18 & 14 & -22 & 3,00 & 3,30 & 10,00 & 2,81 & 2,59 & $-8,00$ & 9 & 0,71 \\
\hline Residente & \multicolumn{5}{|c|}{ Mensaje (según signo) } & \multicolumn{8}{|l|}{ Causa } \\
\hline Residente 4 (caso 1) & \multicolumn{5}{|c|}{ Ni EP ni tendencia validan MEC } & \multicolumn{8}{|c|}{$M E C \geq 5$, EP negativa o nula, tendencia negativa o nula } \\
\hline Residente 6 (caso 2) & \multicolumn{5}{|c|}{ EP valida MEC } & \multicolumn{8}{|c|}{ MEC positivo, EP positiva, no hay tendencia } \\
\hline Residente 13 (caso 3) & \multicolumn{5}{|c|}{ EP no valida MEC, sí tendencia } & \multicolumn{8}{|c|}{ MEC positivo, EP positiva, no hay tendencia } \\
\hline
\end{tabular}


profesionales y, en consecuencia, la calidad de vida de nuestros residentes. Debemos intentar que la metodología sea atractiva, intuitiva, gráfica y visual, y que, en ningún caso, por ver las hojas no veamos el bosque. Los usuarios, la psicóloga y las terapeutas, deben concretar sus necesidades y, por ende, los recursos destinados para cubrirlas. Los instrumentos a disposición de los profesionales de la residencia San José de la Montaña no pueden ser tan complejos ni teóricos que resulten inservibles para resolver los problemas que la gestión diaria de un geriátrico presenta. Ante todo, el método ha de ser concreto en su conceptualización, práctico en su aplicación y sometible a verosimilitud. Valga como ejemplo de este ideario la Figura 8, que representa los resultados obtenidos para el caso 2 (residente con una puntuación MEC que pasa de 32 a 34 puntos $(\Delta=6 \%)$, una ponderación media que se incrementa en 0,20 puntos $(\Delta=4 \%)$ y una tendencia que lo hace en 0,16 puntos $(\Delta=3 \%)$ para un coeficiente $r$ de Pearson igual a 0,87 .

Tabla 3. Cálculos para determinación de tendencias

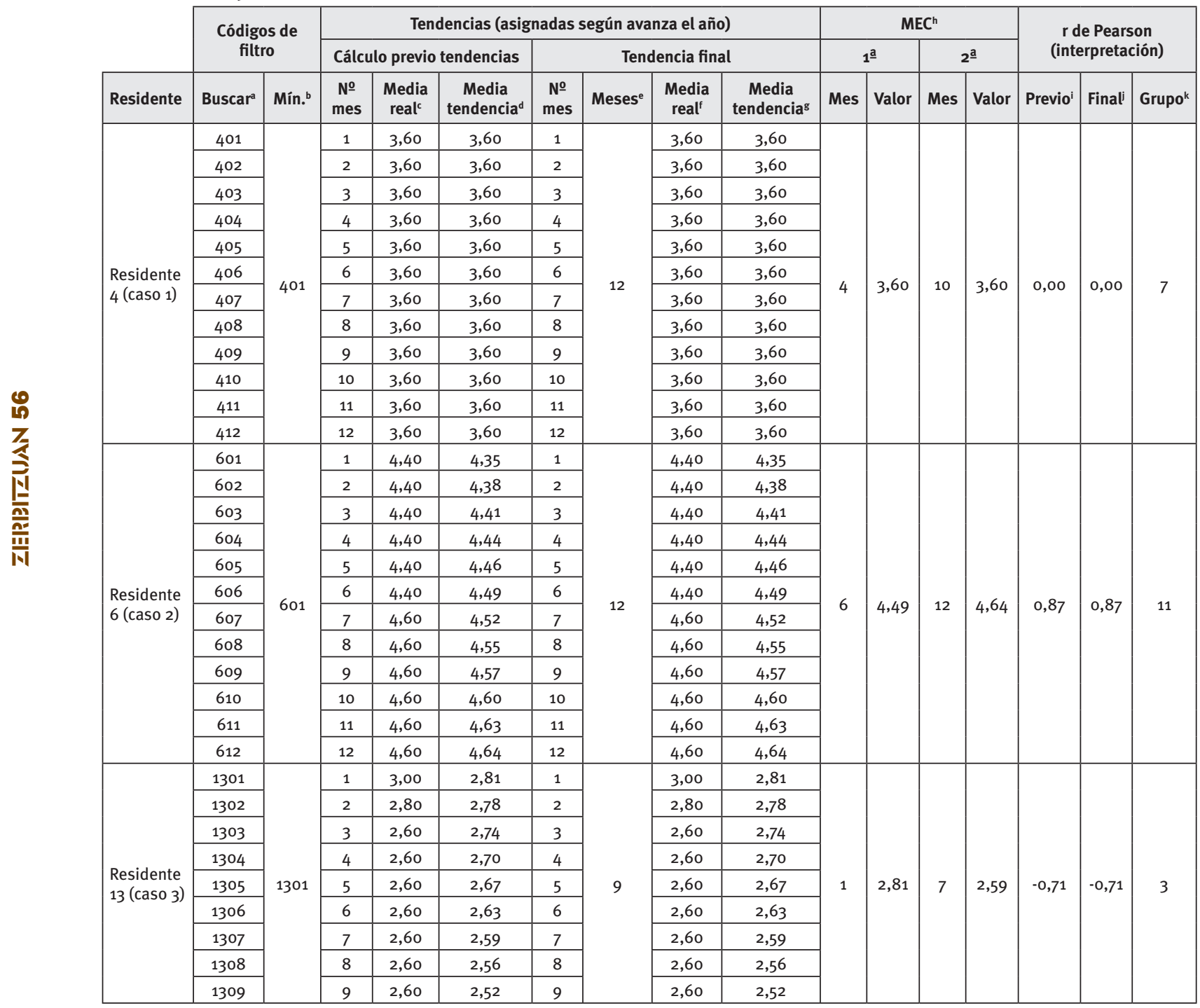

${ }^{a}$ Código combinado de $\mathrm{n}$ - de registro y $\mathrm{n}$ o de mes para personalizar la búsqueda de datos en la matriz correspondiente.

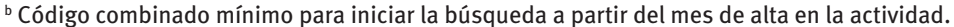

c Promedio mensual personalizado de las ponderaciones otorgadas por las terapeutas en cada función cognitiva.

d Estimación de valor para cada mes como resultado de la recta de correlación lineal. A medida que se añaden evaluaciones mensuales, los valores de la pendiente y el término independiente de la recta de regresión se van ajustando.

e Número de meses de observación, para asegurarse de que, al menos, la nube de puntos está compuesta por tres elementos.

${ }^{\mathrm{f}}$ Mismo concepto que el explicado en la nota ${ }^{c}$, pero corregidas las incongruencias que, por diferentes razones, pueden imposibilitar su cálculo sin adaptar la fórmula correspondiente de la hoja de cálculo (por ejemplo, cuando una secuencia empieza en febrero y, por tanto, enero no existe, y el resultado de la programación informática es un mensaje de error tipo ‘\#¡VALOR!', ‘\#¡DIV/o!', etc.).

${ }^{\mathrm{g}}$ Concepto análogo al anterior.

${ }^{\text {h }}$ Mes de la valoración con el Mini-examen Cognitivo de Lobo (MEC) y valor de tendencia registrada en el mismo, según recta de regresión.

i Coeficiente de correlación $r$ de Pearson para una serie de datos determinada (no menor de tres elementos ni mayor de doce).

'Mismo coeficiente, resueltos los mensajes de error si los hubiere.

${ }^{k}$ Asignación de uno de los trece grupos en que dividimos la interpretación del valor del coeficiente de correlación.

Fuente: Elaboración propia. 

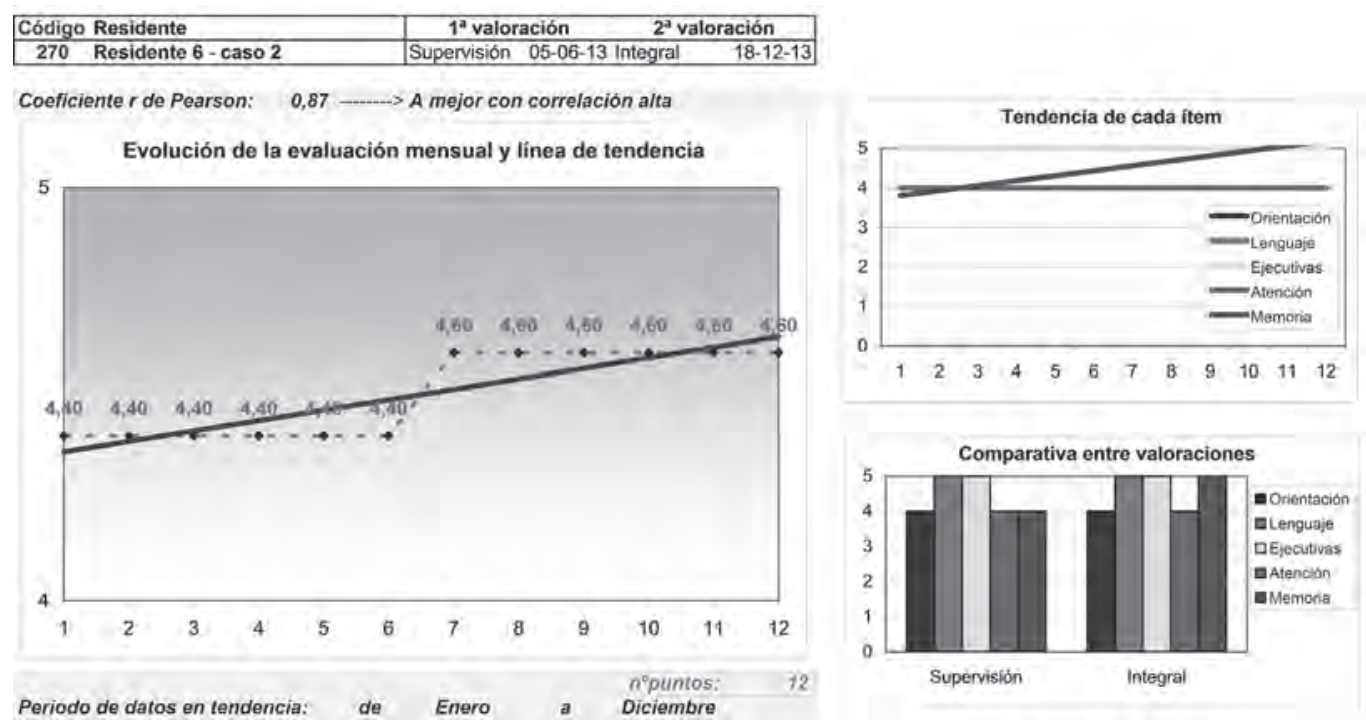

Fuente: Elaboración propia.

\section{Transferibilidad a las actividades sociales}

La transferibilidad de la experiencia también se está produciendo internamente entre las áreas del servicio de atención psicosocial de San José de la Montaña. Una vez comprobada la validez práctica de la metodología diseñada en una dinámica de prueba-error, se ha exportado la misma para la gestión de las actividades sociorrecreativas y de terapia ocupacional del centro (bingo, puzles, lectoescritura, música y biografía, creación y relajación, manualidades y juegos). Mediante el modelo desplegado para la gestión de los programas de estimulación cognitiva, adaptamos los registros (seguimiento mensual de actividades y evaluación práctica) y la explotación de datos a los requerimientos del área social de nuestra residencia. Si bien la metodología es semejante, la definición de ítems a valorar por las terapeutas es específica para este tipo de actividades. En concreto, se ha consensuado la valoración de los conceptos indicados en el Cuadro 8.

La analogía entre las actividades es un hecho lógico. En ambos casos, se da una distribución previa de residentes por grupos conforme a determinados criterios, se pondera la percepción de las terapeutas conforme a una escala y se instrumentaliza la información individual y grupalmente. La única diferencia se halla en qué se evalúa en cada caso: las desviaciones en el MEC, para actividades de estimulación cognitiva; y el cumplimiento o no de las expectativas para cada residente, en el caso de actividades sociales. Dada la dificultad en medir la esperanza en que los objetivos sociales de cada residente se cumplan, la tabla de interpretaciones del coeficiente $r$ de Pearson queda reducida a cinco categorías (Cuadro 9).

\begin{tabular}{|l|l|l|l|l|l|l|}
\hline \multicolumn{6}{|l|}{ Cuadro 8. Ítems evaluados en los programas de terapia ocupacional y actividades sociorrecreativas } \\
\hline Puntuación & Participación & Papel desempeñado & Destreza & Motivación & Actitud \\
\hline 1 & Mal & Pasivo & Baja & Mala & Mala & Nulas \\
\hline 2 & Regular & Disgregador del grupo & Regular & Regular & Regular & Puntuales \\
\hline 3 & Bien & Activo & Normal & Buena & Buena & Ocasionales \\
\hline 4 & Muy bien & Líder & Alta & Muy buena & Muy buena & Estables \\
\hline
\end{tabular}

Fuente: Elaboración propia.

\begin{tabular}{|c|c|c|l|}
\hline Cuadro 9. Adaptación de los intervalos de la interpretación de los valores de la r de Pearson \\
\hline Valor & Valor medio & Grupo & Interpretación \\
\hline$[-1,00,-0,70]$ & $-0,85$ & 1 & A peor, con correlación alta/muy alta \\
\hline$[-0,69,0,01]$ & $-0,35$ & 2 & A peor, con correlación baja/moderada \\
\hline 0,00 & 0,00 & 3 & Sin tendencia \\
\hline$[0,01,0,69]$ & 0,35 & 4 & A mejor, con correlación alta $/ \mathrm{muy}$ alta \\
\hline$[0,70,1,00]$ & 0,70 & 5 & A mejor, con correlación baja/moderada \\
\hline
\end{tabular}

Fuente: Elaboración propia. 
Quizás alguien podría deducir que establecer expectativas es lanzar apriorismos. Nada más alejado de la realidad. En nuestro centro, la determinación de un grupo de correlación u otro para cada residente se basa en la interpretación de la evolución de su estado cognitivo y, asimismo, en los conocimientos adquiridos mediante la propia experiencia de la convivencia con nuestros mayores. A diferencia de la estimulación cognitiva, la validación empírica de las expectativas se determinará únicamente mediante los valores estimados según funciones rectilíneas de regresión, sometidas a seguimiento trimestral para corregir tendencias desviadas de cada objetivo personal. Por lo demás, el modelo se aplica en idéntica versión y tratamiento.

\section{Indicadores enfocados hacia la innovación}

No pretendemos describir el circuito de información que hemos diseñado en la residencia para calcular los valores de los indicadores relacionados en nuestro cuadro de mando. Tan sólo queremos exponer que nuestra organización siempre se ha caracterizado por defender modelos de gestión basados en normas nacionales e internacionales que permitan la sistematización de actividades y la mejora continua que apoyen la toma de decisiones y nos permitan mejorar ha sido históricamente una de nuestras lagunas. De un tiempo a esta parte, cubrir esta carencia se ha convertido en uno de los objetivos principales de nuestra organización.

Desde un comienzo, nuestra residencia ha defendido una práctica profesional enmarcada en unos parámetros teóricos (conocimientos) complementados con otros derivados de la investigación y el análisis de datos. Esta perspectiva nos hizo intuir que el cuadro de mando debía ser desplegado en una batería de indicadores que nos permitiera conocer los resultados de nuestra atención de manera personalizada en cada residente, así como los errores que cometíamos, según lo planificado como excelente, para poder mejorar la calidad de vida de las personas atendidas. Si bien desde un primer momento disponíamos de paneles de indicadores, ninguno de los mismos ha alcanzado el nivel de desarrollo y rigor implantados en la actualidad.

Con anterioridad a la implantación de la experiencia, disponíamos de indicadores de gestión que no llegaban hasta su despliegue en las personas residentes; es decir, conocíamos los resultados a escala global, pero no se llegaba con ese valor a escala individual. Además, no nos permitían establecer correlaciones de ningún tipo (por ejemplo, entre valoraciones psicométricas y evaluaciones prácticas, o entre no asistencia a las actividades y causas de ausencia). En otras palabras, se calculaba cada indicador a escala global, pero no conseguían decir nada acerca de otros datos de interés y, desde luego, no se llegaba a consolidar un cuadro de mando de la organización como suma de los diferentes cuadros de mando de cada área.

Entendemos que sistematizar la recogida selectiva de datos no constituye, en sí mismo, algo especialmente innovador. Lo realmente innovador del método está en la identificación, registro y explotación de los mismos o, lo que es lo mismo, en la sistematización de la información para que todos los agentes intervengan de igual manera. Con un coste mínimo y mucha voluntad, se ha implantado un circuito documental que permite una correcta obtención de datos $y$, en consecuencia, una validación del alcance de los objetivos definidos. Nuestra innovación es precisamente nuestra información o, más concretamente, nuestro sistema de información, que nos lleva a ser capaces de medir la eficacia en la gestión asistencial. En resumen, si entendemos que el desarrollo de herramientas participativas favorece la unicidad de criterios en la gestión de la organización, podemos concluir que esta experiencia ha sido innovadora en los siguientes términos:

- Canales de comunicación claramente definidos conforme a un sistema transparente, accesible, inteligible y modificable por parte de cualquier ámbito del geriátrico.

- Adaptabilidad y flexibilidad del método a los requerimientos de cada área partícipe y centralidad de la atención a las personas mayores.

- Control riguroso y consensuado del cumplimiento de criterios en la introducción de datos.

- Sistematización de seguimientos parciales que permitan la implantación de acciones correctoras.

- Rapidez y fiabilidad en la detección de desviaciones.

- Percepción parcial y global del programa de actividades del centro mediante indicadores objetivos, cuantificables y comparables.

- Capacidad integradora de la información, que facilite la definición de proyectos en una dinámica de mejora continua.

Detrás de cada proceso de gestión asistencial se esconde un arduo trabajo de conciliación de ideas, consenso de enfoques, definición de estrategias, utilización de técnicas y control de resultados propio de cualquier proyecto de $I+D+i$. Este enfoque origina que quienes componen nuestra residencia estén imbuidos de conceptos como innovación, desarrollo, medición, comparación, registro o desviación, por citar algunos términos usuales en nuestra gestión diaria. La implicación del personal a todos los niveles constituye la base sobre la que se asienta la implantación de la buena práctica y la que asegura, en definitiva, una toma de decisiones avalada por datos fidedignos. 


\section{Bibliografía}

CALVO, F. (1990): Estadística aplicada, Ediciones Deusto.

GÓMEZ ORDOKI, A. (2001): Sistema modular de costes y financiación de centros residenciales, Gizartekintza.

GOODGLASS, H. et al. (2005): Evaluación de la afasia y de trastornos relacionados, Madrid, Editorial Médica Panamericana.

LETURIA, F. J. et al. (2001): La valoración de las personas mayores: evaluar para conocer, conocer para intervenir. Manual práctico, Cáritas Española Editores.

LOBO, A. et al. (1999): “Revalidación y normalización del Mini-examen Cognoscitivo (primera versión en castellano del Mini-mental State Examination) en la población general geriátrica", Medicina Clínica (Barcelona).
LOBO, A. et al. (1979): “El Mini-examen Cognoscitivo: un test sencillo, práctico para detectar alteraciones intelectivas en pacientes médicos", Actas Lusoespañolas de Neurología y Psiquiatría, $\mathrm{n}-3$, págs. 189-202.

PEÑA-CASANOVA, J. P. (2005): Programa integrado de exploración neuropsicológica. Test Barcelona revisado, Masson.

REY, A. (2003): Test de copia de una figura compleja, Madrid, TEA.

YANGUAS, J. et al. (1998): Intervención psicosocial en gerontología, Cáritas Española Editores.

VV.AA. (2012): Sistema integrado de gestión de San José de la Montaña, Residencia San José de la Montaña. 